\title{
The miR-25-93-106b cluster regulates tumor metastasis and immune evasion via modulation of CXCL12 and PD-L1
}

\author{
Michele Cioffi ${ }^{1}$, Sara M. Trabulo ${ }^{1,2}$, Mireia Vallespinos ${ }^{1}$, Deepak Raj ${ }^{2}$, Tony Bou \\ Kheir ${ }^{2}$, Meng-Lay Lin², Julfa Begum², Ann-Marie Baker ${ }^{3}$, Ala Amgheib², Jaimy \\ Saif $^{4}$, Manuel Perez ${ }^{5}$, Joaquim Soriano ${ }^{5}$, Manuel Desco $6,7,8$, Maria Victoria Gomez- \\ Gaviro $^{6,7,8}$, Lorena Cusso ${ }^{6,7,8}$, Diego Megias $^{5}$, Alexandra Aicher ${ }^{1,2}$, Christopher \\ Heeschen ${ }^{1,2}$ \\ ${ }^{1}$ Stem Cells \& Cancer Group, Spanish National Cancer Research Centre (CNIO), Madrid, Spain \\ ${ }^{2}$ Stem Cells in Cancer \& Ageing, Barts Cancer Institute, Queen Mary University of London, London, UK \\ ${ }^{3}$ Centre for Tumour Biology, Barts Cancer Institute, Queen Mary University of London, London, UK \\ ${ }^{4}$ School of Clinical Sciences, University of Bristol, Bristol, UK \\ ${ }^{5}$ Confocal Microscopy Unit, Centro Nacional de Investigaciones Oncológicas, Madrid, Spain \\ ${ }^{6}$ Departamento de Ingenieria Biomedica e Ingeniería Aeroespacial, Universidad Carlos III de Madrid, Leganés, Spain \\ ${ }^{7}$ Instituto de Investigación Sanitaria Gregorio Marañón, Madrid, Spain \\ ${ }^{8}$ Centro de Investigación Biomédica en Red de Salud Mental (CIBERSAM), Madrid, Spain \\ Correspondence to: Alexandra Aicher, email: aicher_a@yahoo.com \\ Christopher Heeschen, email: c.heeschen@qmul.ac.uk \\ Keywords: metastasis, CD274, bone marrow, stromal niche, MDSC
}

Received: June 29, $2016 \quad$ Accepted: January 10,2017 Published: February 17, 2017

\section{ABSTRACT}

The stromal microenvironment controls response to injury and inflammation, and is also an important determinant of cancer cell behavior. However, our understanding of its modulation by miRNA ( $\mathrm{miR}$ ) and their respective targets is still sparse. Here, we identified the miR-25-93-106b cluster and two new target genes as critical drivers for metastasis and immune evasion of cancer cells. Using miR-25-93-106b knockout mice or antagomiRs, we demonstrated regulation of the production of the chemoattractant CXCL12 controlling bone marrow metastasis. Moreover, we identified the immune checkpoint PD-L1 (CD274) as a novel miR-93/106b target playing a central role in diminishing tumor immunity. Eventually, upregulation of miR-93 and miR-106b via miR-mimics or treatment with an epigenetic reader domain (BET) inhibitor resulted in diminished expression of CXCL12 and PD-L1. These data suggest a potential new therapeutic rationale for use of BET inhibitors for dual targeting of cancers with strong immunosuppressive and metastatic phenotypes.

\section{INTRODUCTION}

The bone marrow (BM) stromal niche harbors and controls hematopoietic stem cells (HSC) [1], and also plays a critical role in the recruitment and survival of normal and neoplastic cells via production of chemoattractants. Still, our understanding of the epigenetic regulation of the stromal niche during homeostasis and in response to injury or tumorigenesis remains very limited $[1,2]$. Therefore, we studied the role of microRNA (miR) in regulating the stromal niche. MiR are short, non-coding RNAs regulating target mRNAs. Base pair interactions between miR and target mRNAs within the 3'UTR (untranslated region) result in the degradation of the target mRNAs or modulation of their translation. Using tissue ischemia as a model for activating the BM niche, we found that the miR-25-93-106b cluster was most prominently upregulated encouraging us to validatein silico predicted targets of this cluster, i.e. the chemokine CXCL12 (stromal cell-derived factor-1; SDF-1), ligand for the chemokine receptor CXCR4, and the immune modulator CD274 (programmed cell death ligand-1; PD-L1), which binds to CD279 (PD-1). 
CXCL12 is a key attraction and retention signal for stem cells including cancer stem cells [3,4] via activation of its receptor CXCR4. Cells expressing strongly CXCL12 in the stromal niche are mostly endothelial cells and perivascular mesenchymal stromal cell populations including cancer-associated fibroblasts $[5,6]$, and CXCL12 levels are variably modulated in response to local or remote pro-inflammatory stimuli [7-9]. The PDL1 - PD-1 signaling pathway efficiently inhibits T-cell activation $[10,11]$ and growing evidence demonstrates that blockade of PD-1 or its ligand PD-L1 significantly enhances anti-tumor immunity resulting in durable tumor regression in a sizable fraction of patients with advanced cancers [12]. Therefore, advancing our understanding of the underlying regulatory mechanisms for these two critical pathways may also provide the basis for the development of more efficient cancer treatments.

\section{RESULTS}

\section{Upregulation of the miR-25-93-106b cluster in the $\mathrm{BM}$ stromal niche in response to remote tissue insult}

To study the role of miR in the regulation of the stromal niche, we examined changes in miR expression in $\mathrm{BM}$ stromal cells in response to tissue insult (Figure 1A). Considering that many cancers are poorly vascularized and invested with inflammation [13], we used two reproducible and hypothesis-generating model systems, unilateral hind limb ischemia and total body irradiation (TBI), which can also be applied to respective knockout mice in a timely fashion. First, we analyzed the BM stroma in the contralateral, non-ischemic hind limb of the hind limb ischemia model (Supplementary Figure 1A-1D). We found all three members of the miR-25-93-106b cluster to be consistently increased (Figure 1A). Upregulation of miR-25, 93, and $106 \mathrm{~b}$ was confirmed by qRT-PCR in sorted CD45- BM cells and CD45-CD140a ${ }^{+} \mathrm{SCA}-1^{+}$ mesenchymal progenitor cells, respectively (Figure 1B) [14]. In line with the hypothesis that miR-25-93-106b is important for tissue regeneration, induction of hind limb ischemia or myocardial infarction in miR-2593-106b KO mice resulted in a significantly reduced limb perfusion and larger infarct sizes, respectively (Supplementary Figure 1A-1E). In addition, miR-25-93106b KO mice undergoing myocardial infarction showed a strong desmoplastic response in line with an increased fibroblastoid colony-forming activity detected in miR-2593-106b KO mice (Supplementary Figure 4). Consistently, in pancreatic tumors as a prototypic cancer with extensive desmoplasia, we also found a suppression of the miR25-93-106b cluster in stromal cells relative to the cancer cells (Supplementary Figure 2A). These data were also further confirmed by assessment of freshly isolated and sorted stromal and cancer cells by qRT-PCR showing lower expression of miR-93 and miR-106b in stromal cells than cancer cells (Supplementary Figure 10). In addition, we performed in situ hybridization (ISH) for miR-106b visualizing miR-106b expression in primary pancreatic cancer and liver metastasis, thereby confirming expression in both stromal cells and cancer cells as well as inverse target regulation (Supplementary Figure 11).

\section{Enhanced recruitment and invasion of bone marrow cells upon downregulation of miR- $93 / 106 \mathrm{~b}$ in the stromal niche}

Tissue repair and tumor development are accompanied by the influx of various cells including BM cells (BMC). We used DiD-labeled HSC-containing BMC freshly derived from WT mice to study their capacity to home to the BM of irradiated miR-25-93-106b KO vs. WT mice (Figure 2A/2B). We observed that $\mathrm{DiD}^{+}$WT BMC were more efficiently recruited to the BM stroma of miR25-93-106b KO mice as compared to WT BM suggesting that miR-25-93-106b KO mice produce higher levels of chemoattractants following tissue insult, i.e. total body irradiation (TBI). To validate individual cluster members as crucial for the observed phenotype, we studied the invasion of WT BMC towards CD45- WT BM-derived mesenchymal stem cells (WT-MSC) that were pre-treated with control or antagomiR for miR-25, 93, and 106b. We found enhanced invasion/migration through the Matrigel $^{\mathrm{TM}}$ layer for WT-MSC treated with antagomiR for miR-93 and $106 \mathrm{~b}$, but not for miR-25 (Figure 2C/Figure 5E).

To further corroborate these findings, we used a distinct setting where mice were exposed to TBI followed by BM transplantations using low numbers $\left(10^{5}\right)$ of donor $\mathrm{Katushka}^{+}$WT BMC so that successful engraftment was critically dependent on a proficient BM niche. As opposed to remote tissue ischemia, TBI suppressed the expression of the miR-25-93-106b cluster (Supplementary Figure 2B). Survival of mice following WT BM transplantation was almost two-fold higher for miR-25-93-106b KO recipients as compared to WT recipients (Figure 2D). This was in line with increased numbers of Katushka ${ }^{+}$ WT BM cells in the BM of miR-25-93-106b KO recipient mice (Figure 2E) suggesting that more WT BM cells had migrated to the TBI-injured BM of miR-25-93-106b KO mice. In line with these data, $\mathrm{WT} \mathrm{CD} 45^{+} \mathrm{C}-\mathrm{KIT}^{+} \mathrm{BMC}$ showed enhanced invasiveness when migrating towards adherently growing miR-25-93-106b KO MSC relative to WT MSC cell layers (Supplementary Figure 2C).

Reverse experiments using miR-25-93-106b KO $\mathrm{BM}$ cells transplanted into WT recipients resulted in impaired survival of the mice as compared to WT mice transplanted with WT BM cells (Supplementary Figure 3A). The impaired $\mathrm{BM}$ reconstitution by $\mathrm{KO} \mathrm{BM}$ could also be demonstrated by reduced levels of plateletproducing megakaryocytes and neutrophilic granulocytes resulting in prolonged bleeding times and neutropenia 
A

\section{CD45- ${ }^{-}$tromal cells in vivo}

\begin{tabular}{lc} 
miRNA & $\begin{array}{c}\text { Ischemia (I) I } \\
\text { Sham (S) }\end{array}$ \\
\hline miR-486-5P & 0.44488 \\
\hline miR-690 & 0.65118 \\
\hline miR-103 & 0.65811 \\
\hline miR-25 & 2.88372 \\
\hline miR-26A & 3.16524 \\
\hline miR-106A & 3.20936 \\
\hline miR-93 & 3.28852 \\
\hline miR-106b & 4.18992 \\
\hline miR-21 & 5.63038 \\
\hline miR-142-5P & 5.81643 \\
\hline Let-7F & 6.52930 \\
\hline
\end{tabular}

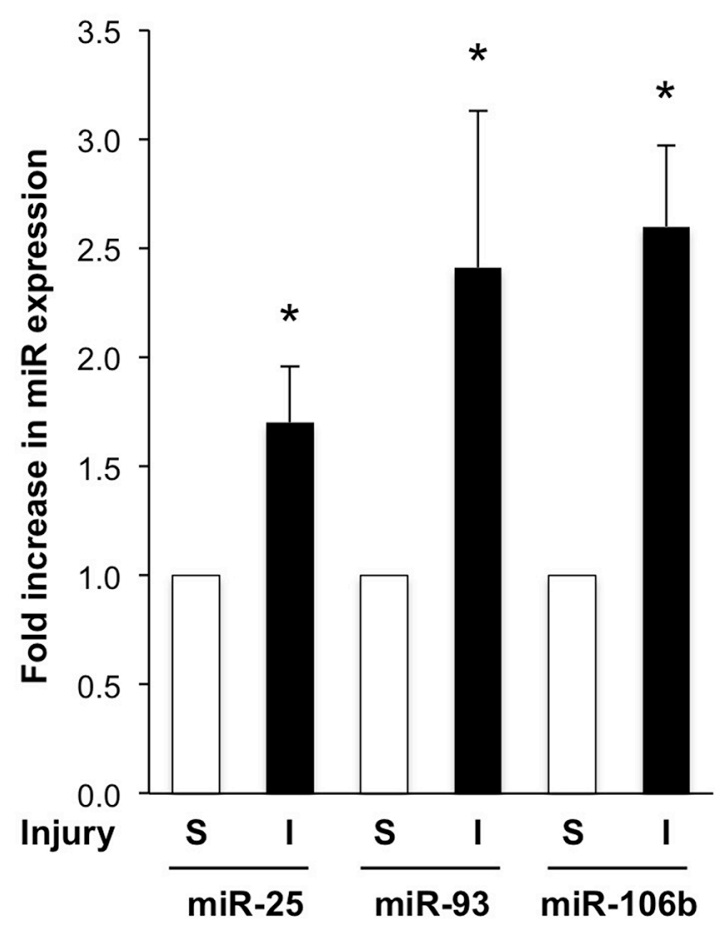

B
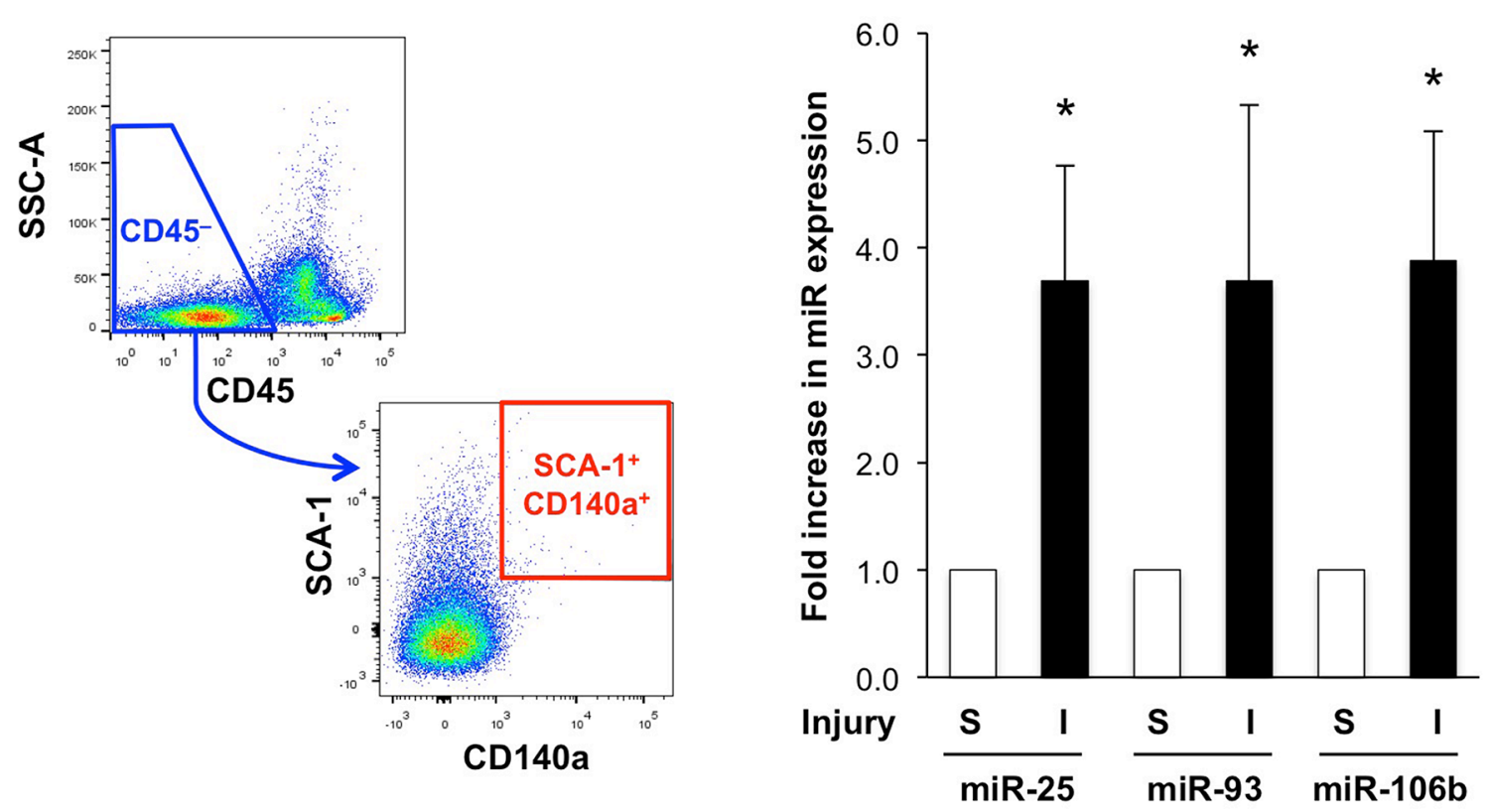

Figure 1: Ischemia-induced up-regulation of miR-25-93-106b in the bone marrow (BM) stromal niche. A. MiRNA array for $\mathrm{CD} 45^{-} \mathrm{BM}$ stromal cells following sham surgery (S) or ischemia induction (I). Grey background: most prominently upregulated miR, red: members of the miR-25-93-106b cluster (left). Validation by qRT-PCR; $n=5-6, * p<0.05$ (right panel). B. Gating strategy (left) and quantification (right) of $\mathrm{CD} 45^{-} \mathrm{CD} 140 \mathrm{a}^{+} \mathrm{SCA}-1^{+}$mesenchymal progenitor cells. Quantification by qRT-PCR; $\mathrm{n}=3-4,{ }^{*} \mathrm{p}<0.05$. 



D

E
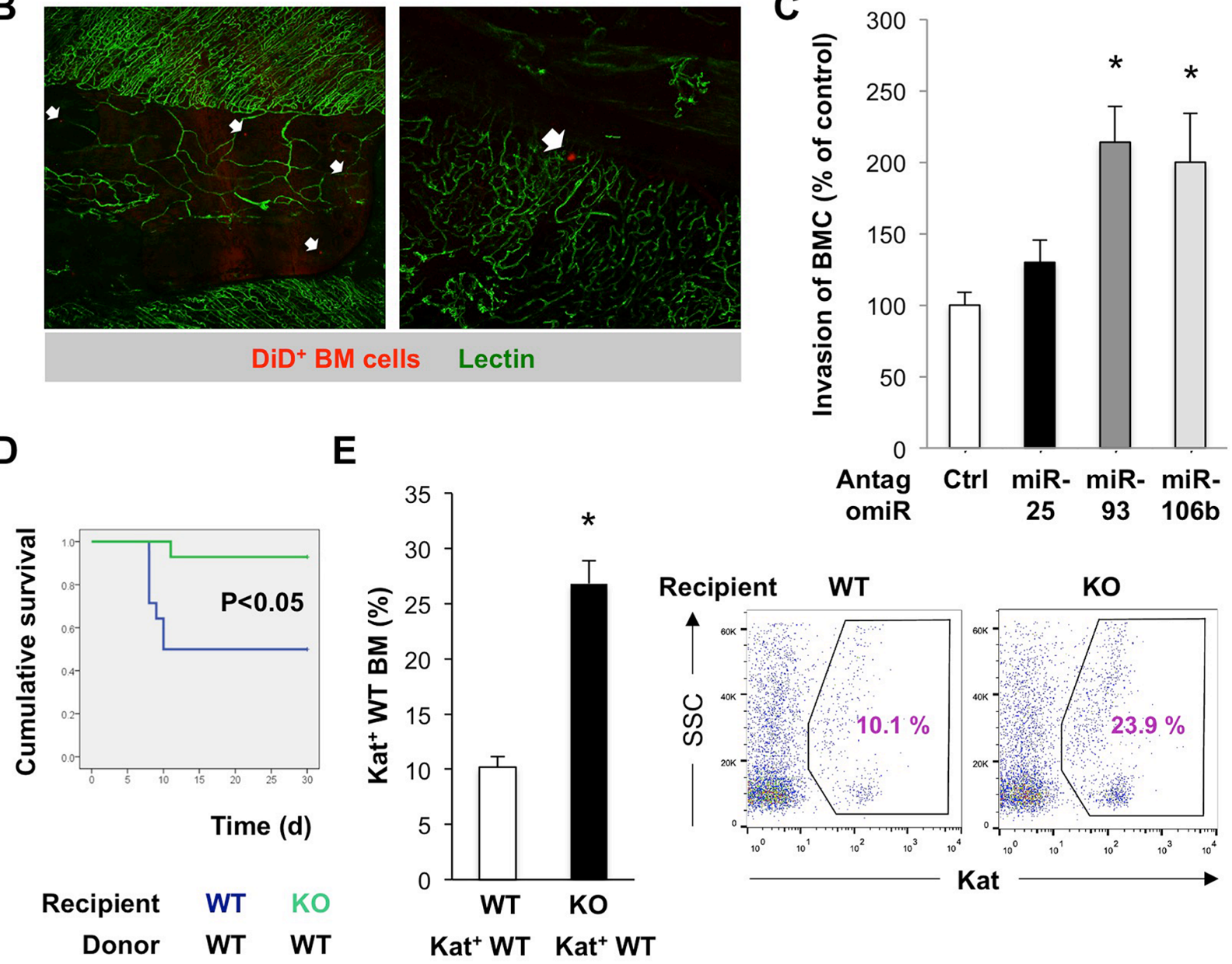

$\mathrm{Kat}^{+}$WT $\mathrm{Kat}^{+}$WT

Figure 2: Enhanced recruitment and invasion of bone marrow cells upon downregulation of miR-93/106b in the stromal niche. A. In vivo homing of DiD-labeled BMC to the irradiated BM of WT vs miR-25-93-106b KO mice, $\mathrm{n}=4$, * $\mathrm{p}<0.05$ (left). Representative flow cytometry (right). B. Ex vivo confocal analysis of irradiated WT sternal BM 48 hours after i.v. injection of DiD $\mathrm{BM}^{+}$ cells (red). Vascularization is identified by lectin staining (green). Homing of individual $\mathrm{DiD}^{+} \mathrm{BM}$ cells is indicated (arrows). C. In vitro invasion of BMC towards WT-MSC in the presence or absence of miR-25/93/106b antagomiR. $n=7, * \mathrm{p}<0.05$ for miR-25/93/106b antagomir treatment versus control antagomir. D. Kaplan-Meier survival curves of recipient WT vs KO mice following WT BM transplantation; n=14, $* \mathrm{p}<0.05$. E. Homing of $\mathrm{Kat}^{+} \mathrm{WT}$ BM cells to the BM of irradiated WT vs KO mice; $\mathrm{n}=3$, $* \mathrm{p}<0.05$ (left). Representative flow cytometry is shown (right). 
(Supplementary Figure 3B) as well as reduced levels of granulocyte and megakaryocyte progenitors in in vitro colony-forming unit (CFU) formation assays (Supplementary Figure 3C). Interestingly, while myeloid progenitors were also reduced, fibroblast progenitors assessed as fibroblastoid CFU (CFU-F) were increased in the $\mathrm{BM}$ of miR-25-93-106b $\mathrm{KO}$ mice, which may at least in part rationalize the enhanced desmoplastic response in these mice (Supplementary Figure 1E) that is also characteristic of many tumors [13]. Consistently, fibroblast activation protein $(\mathrm{FAP})^{+} \mathrm{CD} 45^{-}$fibroblasts and $\mathrm{FAP}^{+} \mathrm{CD}^{2} 5^{+}$fibrocytes were both increased in the $\mathrm{BM}$ and peripheral blood of miR-25-93-106b KO mice (Supplementary Figure 4A/4B). About $60 \%$ of $\mathrm{CD}^{+} 5^{+}$ colony-derived cells were $\mathrm{CD} 11 \mathrm{~b}^{+}$, of which $\sim 3 \%$ were $\mathrm{FAP}^{+}$. Importantly, while peripheral blood-derived fibroblastoid CFU from WT mice exhibited increased numbers of $\mathrm{CD}^{4} 5^{-} \mathrm{C}-\mathrm{KIT}^{+}$vascular progenitors in response to ischemia, miR-25-93-106b KO mice showed impaired mobilization of vascular progenitors into the peripheral blood (Supplementary Figure 4C).

\section{Enhanced recruitment and invasion of cancer cells upon downregulation of miR-93/106b}

To validate these findings in the context of cancer metastasis, we next studied the homing of human Nalm6 cancer cells to the BM as a crucial step in metastasis, which still represents a primary reason for cancerassociated lethality. DiD-labeled Nalm-6 cells were intravenously injected into irradiated miR-25-93-106b KO and WT mice, respectively, and the BM was examined 6 hours afterward showing increased homing to MiR-2593-106b KO BM (Figure 3A). These data were confirmed by ex vivo migration assays employing explanted and slit bones of irradiated miR-25-93-106b KO or WT mice, placed at one end of a flow chamber, while $\mathrm{DiD}^{+} \mathrm{Nalm}-$ 6 cells were placed at the other end, both connected via a microfluidic channel. We found increased numbers of Nalm-6 cells migrating towards miR-25-93-106b KO bone fragments (Figure 3B). DiD ${ }^{+} \mathrm{Nalm}-6$ cells also migrated more efficiently towards irradiated miR-25-93-106b KO BM-derived MSC as compared to WT MSCs (Figure 3C).

\section{Identification of potentially relevant targets for the miR-25-93-106b cluster}

To interrogate the large list of potentially relevant targets modulated by miR-25-93-106b, we isolated CD45- BM stromal cells from miR-25-93-106b KO vs. WT mice following induction of ischemia for 48 hours. We did not only study established targets of the mir-2593-106b cluster i.e. p21 [15], integrin b8 (Itgb8) [16], and transforming growth factor b receptor II ( $T g f b r 2)$ [17], but also in silico predicted targets such as Zeb2 (Supplementary Figure 5), Cxcl12 (Figure 4A), and Cd274
(Figure 6A). Not unexpectedly, all above target genes, except Cd274 (Figure 7A), were downregulated in WT mice in response to tissue insult but were unleashed in miR-25-93-106b KO mice (Figure 4B \& Supplementary Figure 5). For further investigation we selected CXCL12 as an established critical regulator of stem cell homing and mobilization, respectively [18, 19] and PD-L1 and PD1 as a crucial immune checkpoint with strong translational relevance.

\section{The miR-25-93-106b cluster is a negative regulator of $\mathrm{CXCL12}$}

Using 3'UTR Cxcl12 luciferase assays, we first validated that miR-93-5P and miR-106b-5P suppressed luciferase activity establishing $\mathrm{Cxcl12}$ as a miR-935P/106b-5P target (Figure 4C). Moreover, Cxcl12 was downregulated in $\mathrm{CD}^{4} 5^{-} \mathrm{BM}$ stromal cells of WT mice following tissue ischemia, while miR-25-93-106b KO mice showed higher baseline levels for $\mathrm{Cxcl12}$ in sham-treated mice and lack of suppression following tissue ischemia (Figure 4B). These in vivo results were corroborated using $\mathrm{CD}^{-} 5^{-} \mathrm{BM}$ cells treated ex vivo with miR-93/106b antagomiR demonstrating upregulation of Cxcl12 (Figure 4D). Again we pursued TBI as a distinct modality of tissue injury and analyzed the bone marrow after 6 and 24 hours for the expression of CXCL12 using confocal microscopy (Figure 5A/5B). During 24 hours, TBI-induced expression of CXCL12 protein in WT BM stromal niches, but CXCL12 levels were significantly higher in miR25-93-106b KO mice. This was confirmed by qRT-PCR analysis (Figure 5C) and intracellular flow cytometry for CXCL12 (Figure 5D). To functionally validate CXCL12 as a chemokine that is crucial for the observed phenotype, we next studied WT BMC invading and migrating through a Matrigel ${ }^{\mathrm{TM}}$ layer towards adherently growing CD45 BM-derived mesenchymal stem cells (MSC). The specific CXCR4 antagonist AMD3465 abrogated the enhanced invasiveness (Figure 5E) demonstrating that the miR25-93-106b cluster regulates stem cell trafficking via CXCL12 (Figure 5F). In addition, we also corroborated the role of CXCL12 using CRISPR/Cas9-mediated gene editing to create CXCL12 knock-out cells confirming the role for CXCL12 in miR deficiency-induced migration (Supplementary Figure 8).

\section{The miR-25-93-106b cluster targets CD274 in cancer cells}

Next we investigated whether the miR-25-93-106b cluster is also involved in modulating immune tolerance, which is particularly important during tumor cell trafficking and metastasis when cancer cells are directly exposed without a protective tumor microenvironment. Our in silico prediction screen suggested that miR-106b-5P and miR-93$5 \mathrm{P}$ are targeting the checkpoint inhibitor Cd274 (PD-L1) 
A

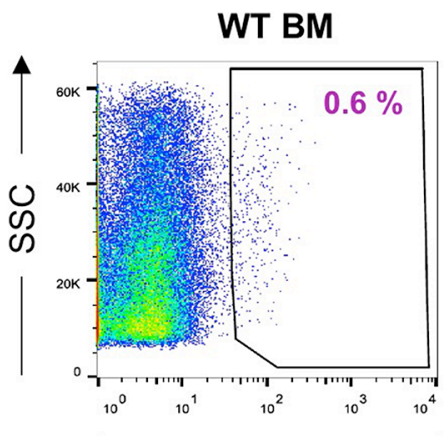

B

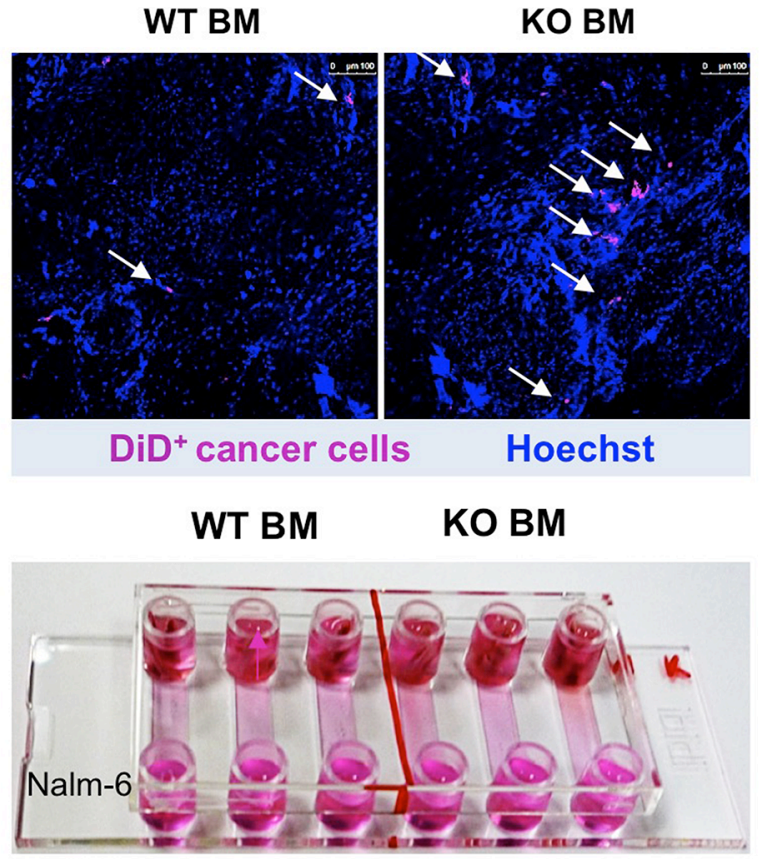

C



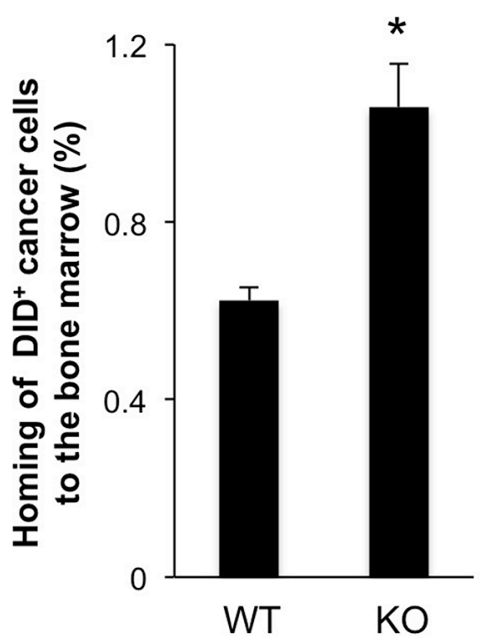
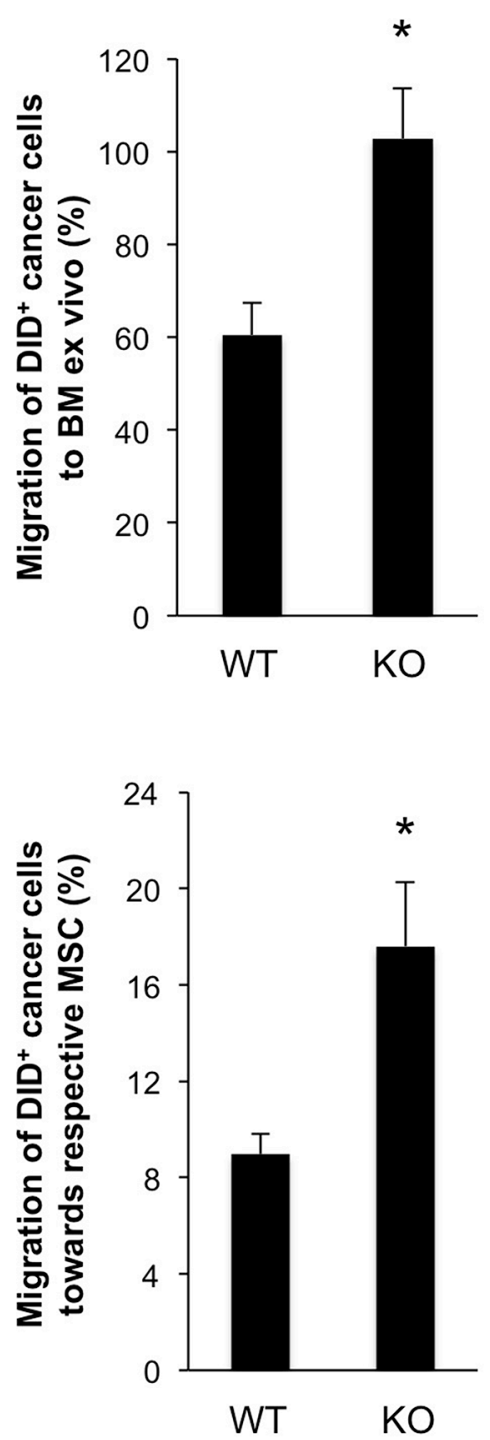

Figure 3: Enhanced recruitment and invasion of cancer cells upon downregulation of miR-93/106b in the stromal niche. A. Number of $\mathrm{DiD}^{+} \mathrm{Nalm}-6$ cells found in the BM of WT vs KO mice 6 hours after injection; $\mathrm{n}=4, * \mathrm{p}<0.05$. Representative flow cytometry (left) and quantification (right). B. Migration of $\mathrm{DiD}^{+} \mathrm{Nalm}-6$ cells to WT and KO BM ex vivo; $\mathrm{n}=6,{ }^{*} \mathrm{p}<0.05$. Representative confocal image (upper left), migration chamber (lower left), quantification (right). C. Migration/invasion of DiD $\mathrm{Nalm}^{+} 6$ cells to WT and KO MSC following irradiation; $\mathrm{n}=4, * \mathrm{p}<0.05$. 
From microrna.org for Cxcl12 NM_021704

C mmu-miR-93/Cxcl12 Alignment

3' gauggacgugcuuguCGUGAAAC 5' mmu-miR-93

mirSVR score: $\quad-1.2974$

1152:5' uacauauauuuuuguGCACUUUu 3' $\mathrm{Cxcl} 12$

PhastCons score: 0.7601

\section{C mmu-miR-106b/Cxcl12 Allgnment}

3' uagACGUGACAGU-CGUGAAAu 5' mmu-miR-106b

| :|:| | I:: IIIIIII

1153:5' acaUaUaUUUUUGUGCACUUUU $3^{\prime} \mathrm{Cxcl12}$

mirSVR score: $\quad-1.2960$

PhastCons score: 0.7601

\section{miR-93/106b}

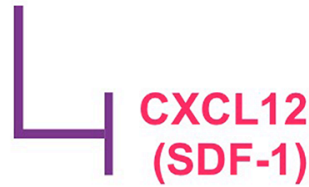

B
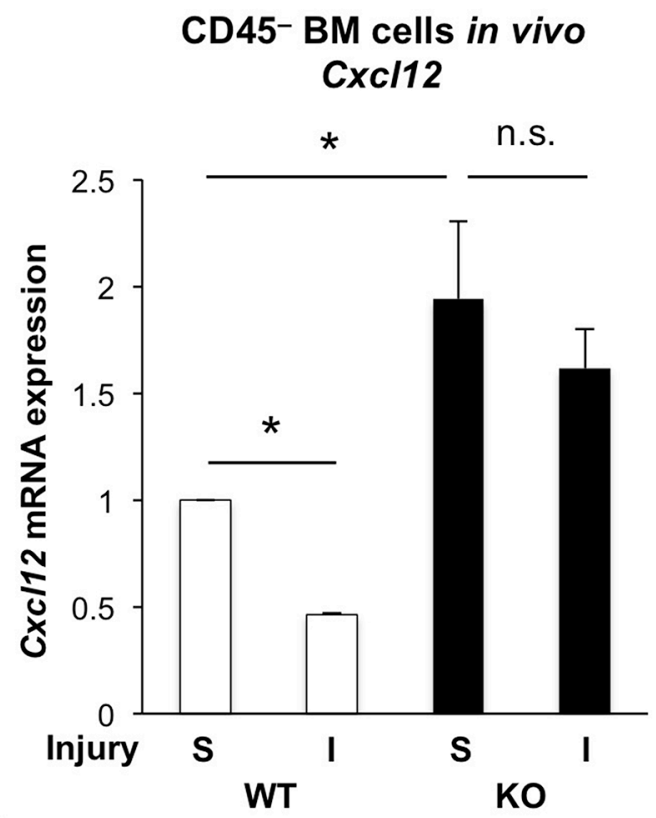

D

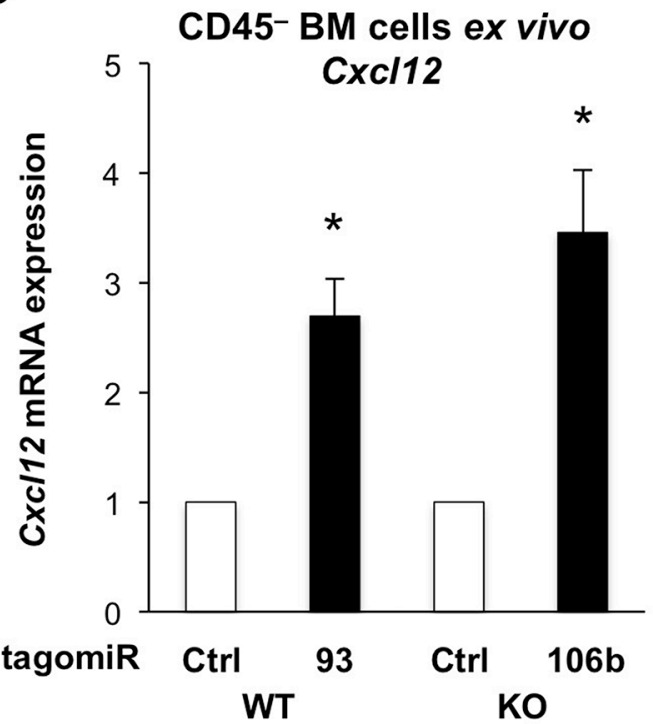

C

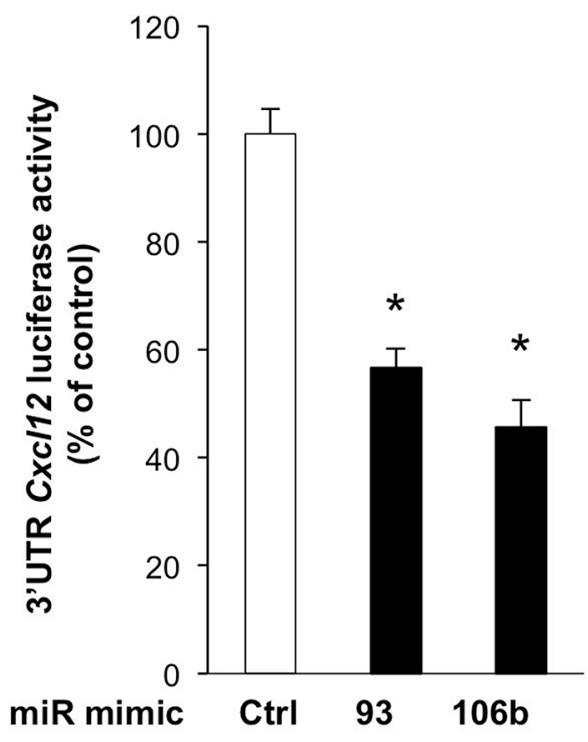

Figure 4: The miR-25-93-106b cluster is a negative regulator of $\mathbf{C x c l 1 2}$. A. In silico prediction of $\mathrm{Cxcl12}$ as miR-93/106b target by www.microrna.org. B. Cxcl12 expression of CD45-BM cells in WT vs miR-25-93-106b KO mice following sham surgery (S) or induction of ischemia (I); $\mathrm{n}=3, * \mathrm{p}<0.05$. C. 3'UTR Cxcl12 luciferase assay in HEK293 cells in the presence or absence of miR-93 and miR-106 mimics; $\mathrm{n}=9,{ }^{*} \mathrm{p}<0.05$. D. Cxcl12 expression in ex vivo $\mathrm{CD} 45^{-} \mathrm{BM}$ cells with or without miR-93/106b antagomiR; $\mathrm{n}=5,{ }^{*} \mathrm{p}<0.05$. 
A

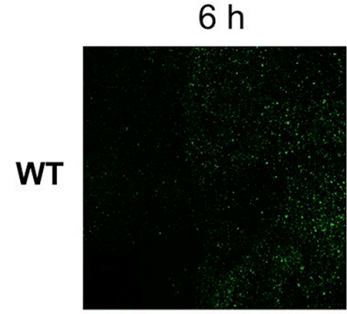

ko
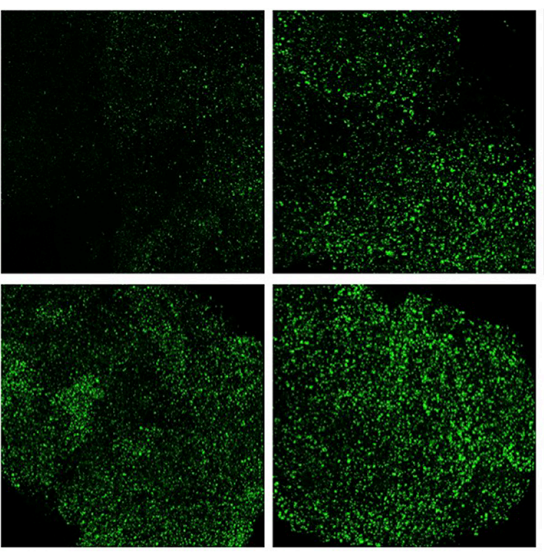

CXCL12

C



unstained

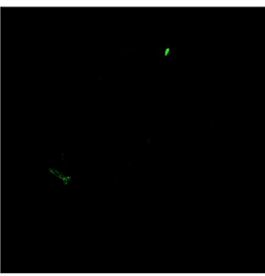

D

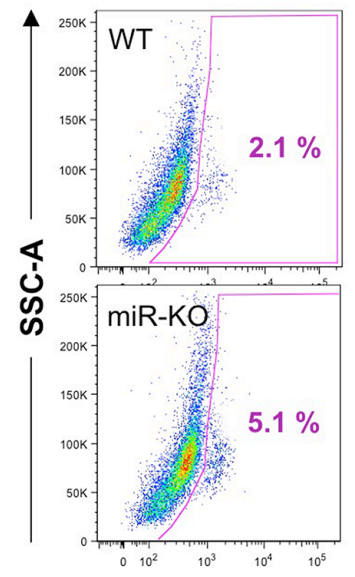

B

WT

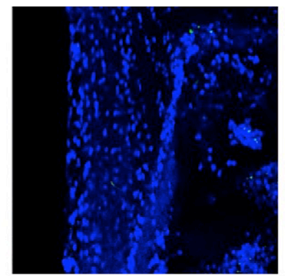

Ko

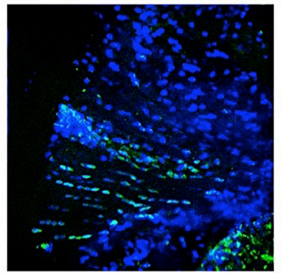

CXCL12 DAPI

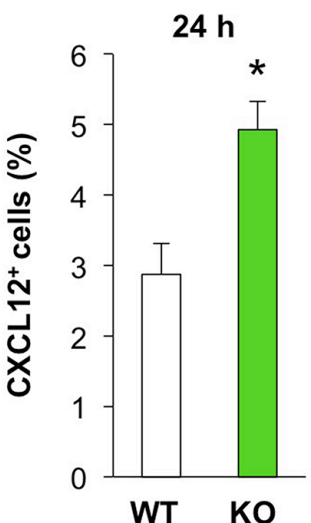

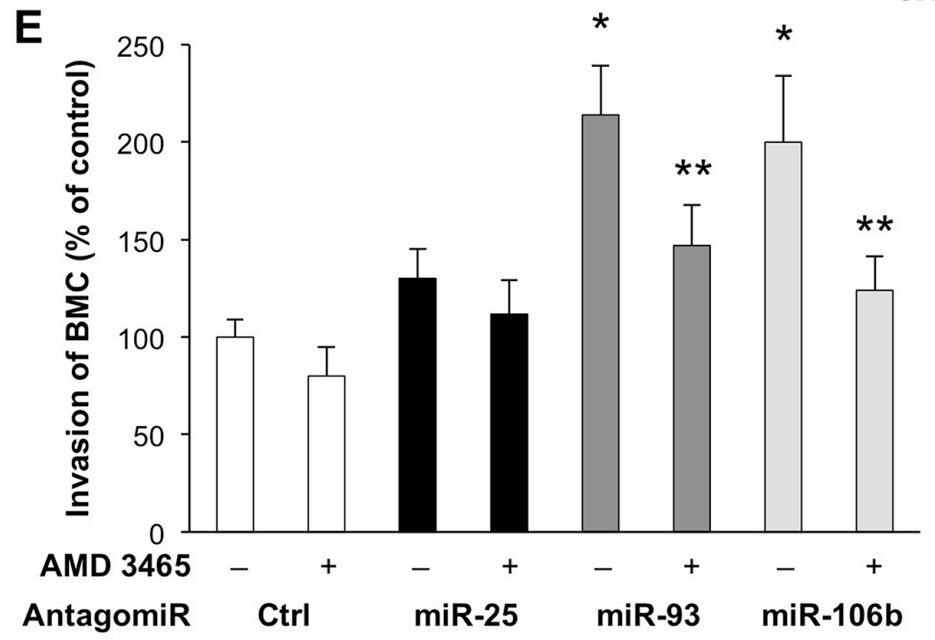



F

Mir-93/106b

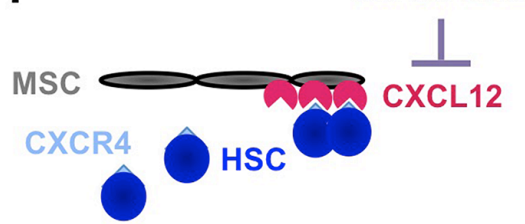

Figure 5: The miR-25-93-106b cluster is a negative regulator of $\mathrm{Cxcl12}$ in the bone marrow stromal niche. A. Ex vivo confocal microscopy analysis for CXCL12 expression in WT vs miR-25-93-106b KO BM cells following in vivo whole body irradiation. Representative images were taken 6 and 24 hours after irradiation. B. High-power confocal microscopy of CXCL12 expression in the BM stromal niche ex vivo. C. Cxcl12 mRNA expression was quantified by qRT-PCR 6 and 24 hours after irradiation; $\mathrm{n}=5, * \mathrm{p}<0.05$. D. Representative flow cytometry of intracellular CXCL12 expression in WT vs KO BM (left) and quantification; $\mathrm{n}=3, * \mathrm{p}<0.05$ (right). E. In vitro invasion of BMC towards WT-MSC in the presence or absence of miR-25/93/106b antagomiR. The CXCR4 antagonist AMD 3465 was used to inhibit CXCL12/CXCR4 signaling. Control groups are replicated from Figure 2C; $=7,{ }^{*} \mathrm{p}<0.05$ for miR-25/93/106b antagomir treatment versus control antagomir, ** $\mathrm{p}<0.05$ for CXCR4 antagonist treatment versus PBS control. Quantification (left) and schematic illustration (right). F. Role of the miR-25-93-106b cluster in the bone marrow niche. Illustration that the bone marrow niche in our in vitro setup is mimicked by MSC expressing CXCL12. 
(Figure 6A), but not any of the other key players expressed on T-cells that induce tolerance such as Pdcd-1, Ctla4, Ido1/2, Lag3, Tim3, Fasl, and Cd80/86 (data not shown). In line with this prediction, primary cancer cells also expressed CD274, which was further enhanced by inducing a more invasive phenotype using macrophage-conditioned medium (Figure 6B) [20]. Surprisingly, however, expression of CD274 was lower in the contained subset of cancer stem cells as compared to their more differentiated progenies (Supplementary Figure 6A), whereas miR-106b5P expression was inversely increased in cancer stem cells (Supplementary Figure 6B); findings that are still in line with previous findings for cholangiocarcinoma CSC [21]. Importantly, expression of CD274 was reduced in bulk cancer cells following treatment with miR-106b-5P and miR-93-5P mimics, respectively (Figure 6C). Intriguingly, dual inhibition of both CXCL12 and CD274 at the mRNA and protein level could be achieved by miR-106b-5P mimics (Figure 6D). Inversely, CD274 expression was enhanced by treatment with miR-106b-5P antagomiR (Supplementary Figure 6C).

\section{The miR-25-93-106b cluster targets CD274 in stromal cells}

In line with above findings for primary cancer cells, we also found that miR-25-93-106b KO mice bear 50\% more CD274+ myeloid $\mathrm{CD} 11 \mathrm{~b}^{+} \mathrm{BM}$ cells as compared to WT mice (Figure 7A \& Supplementary Figure $7 \mathrm{~A} / 7 \mathrm{~B}$ ) and the increase is even further enhanced upon TBI (which reduces expression of miR-25-93106b). Similar or even greater differences were observed for the analysis of freshly isolated untreated splenocytes (Supplementary Figure 7C), splenocytes stimulated with phytohemagglutinin (PHA) to activate $\mathrm{T}$ cells to secrete IFNg as a classical inducer of PD-L1 [22] (Figure 7B), and monocytic myeloid-derived suppressor cells (M-MDSC) (Figure 7C \& Supplementary Figure 7D). Sorted CD274expressing M-MDSC from the peripheral blood of tumorbearing mice showed a diminished expression of CD274 following treatment with miR-93 mimics (Figure 7D). In line with these findings, freshly isolated tumor cells treated with miR-93-5P and miR-106b-5P mimics also exhibited significantly reduced expression of CD274 (Figure 6C). Intriguingly, these effects could be mimicked by treatment with inhibition of the bromodomain and extraterminal (BET) family of proteins, i.e. using OTX015, which resulted in upregulation of both miRs and subsequent suppression of $\mathrm{Cd} 274$ and $\mathrm{Cxcl12}$ (Figure 7E). Similar data were obtained for OTX015 and the expression of Cd274 in primary cancer cells (Supplementary Figure 6D). In addition, we further confirmed the role of the miR-2593-106b cluster for the regulation of CD274 demonstrating that miR-106b deficiency partially prevented the OTX015induced suppression of CD274 (Supplementary Figure 9). Therefore, our data demonstrate that miR-93-5P and
miR-106b-5P negatively regulate CXCL12 and CD274 expression in both cancer cells and MDSC, and that BET inhibitors represent a suitable upstream modality to control expression of CXCL12 and CD274 via transcriptional regulation of the miR-25-93-106b cluster.

\section{DISCUSSION}

The BM stromal niche plays a crucial role for survival, maintenance, and mobilization of stem and progenitor cells as well as cancer (stem) cells via the production of chemoattractsignals such as CXCL12. Our results elucidate how danger signals such as remote ischemia and systemic total body radio-injury mediate signals to the stromal niche through the evolutionary conserved mir-25-93-106b cluster. Specifically, we identified that the cluster members miR-93 and 106b are essential regulators of the BM stromal compartment for cell homing and mobilization, respectively, through targeting CXCL12. Our data were functionally validated by transplanting normal BM cells into secondary hosts, but interestingly, we also found that the mir-25-93-106b cluster altered the receptiveness of the BM for metastatic cancer cells via the same mechanism. Moreover, we provide conclusive evidence that the immune modulator CD274 is another novel target of miR-93/106b, not only in BM (stromal) cells but also in M-MDSC and primary cancer cells. Thus, our data suggest that miR$93 / 106$ b mimics or their transcriptional modulation by bromodomain inhibition could be used for dual targeting of cancers with a strong immunosuppressive and metastatic phenotype.

To date, few miR such as miR-23a and miR-886$3 p$ have been implicated in the regulation of CXCL12 in $\mathrm{BM}$ stromal cells in vitro $[23,24]$. Also, cancer cells and cancer-associated stromal cells showed down-regulation of miR-126, thus enhancing the release of CXCL12 and subsequently recruiting MSCs to further promote tumor cell invasion and metastasis [25]. Importantly, we found that the actual response of the bone marrow stromal niche was dependent on the type of insult. In response to the induction of remote tissue injury, i.e. induction of ischemia, as found in many cancers, we observed members of the miR-25-93-106b cluster to be strongly upregulated resulting in downregulation of CXCL12 in the BM stromal niche. The diminishment of the CXCL12 gradient in the BM niche resulted in the release of stem and progenitor cells and their subsequent mobilization into the peripheral blood and traveling to the site of injury [8]. In contrast, ionizing radiation-induced oxidative stress had previously been demonstrated to alter miR in a time- and dose-dependent manner [26, 27]. Specifically, expression of miR-106b was downregulated in response to higher doses of irradiation [27]. Moreover, irradiation had been reported to upregulate CXCL12, an effect that was reportedly further enhanced by hypoxia [28]. Consistently, 
A

From microrna.org for CD274 NM_021893

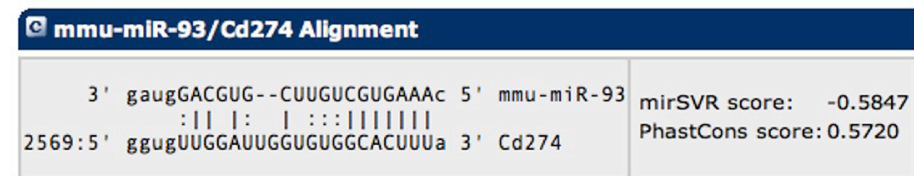

C mmu-miR-106b/Cd274 Alignment

3' uaGACGUGA-CA-GUCGUGAAAu 5' mmu-miR-106b

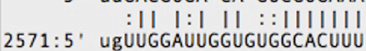
2571:5' ugUUGGAUUGGUGUGGCACUUUa 3' Cd274

mirSVR score: $\quad-0.5738$ PhastCons score: 0.5720

B

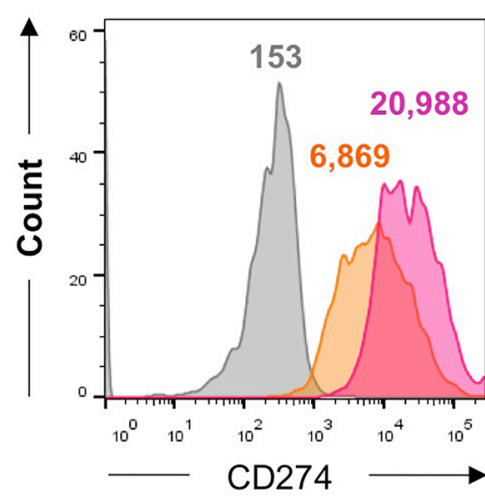

C
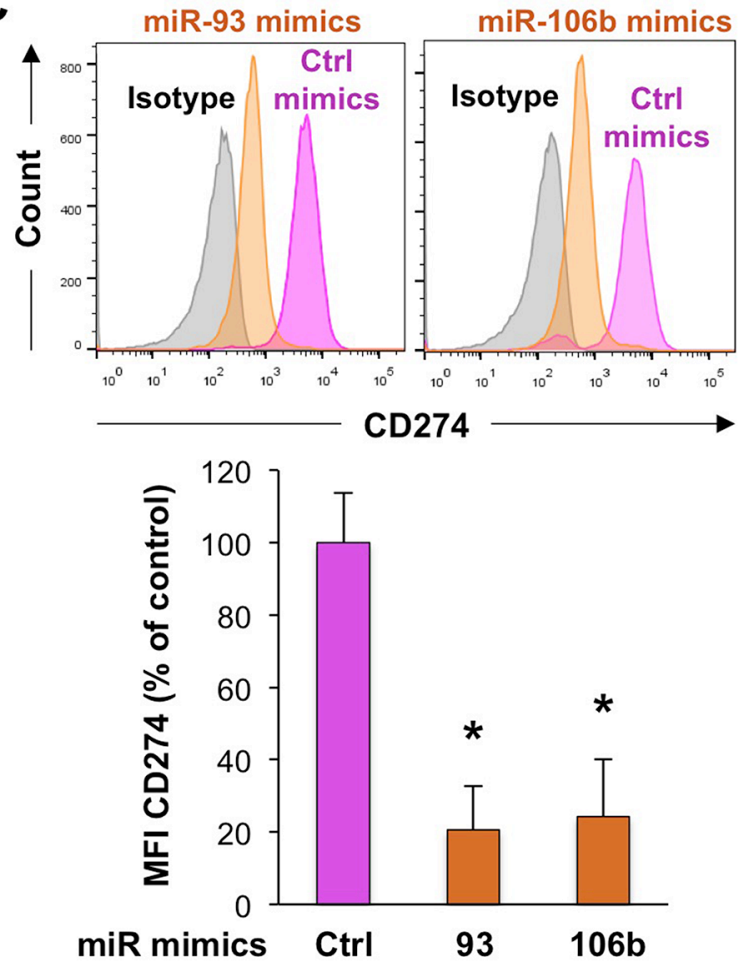

\section{Isotype}

hPDAC
D
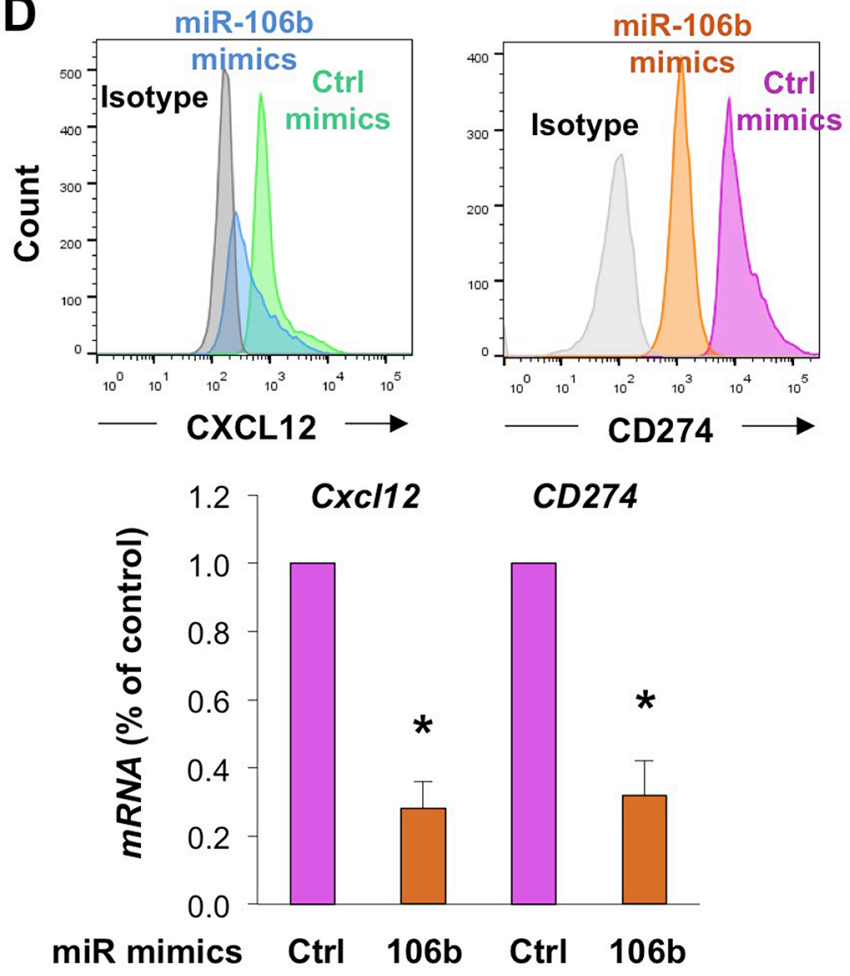

hPDAC + macrophage CM

miR-93/106b

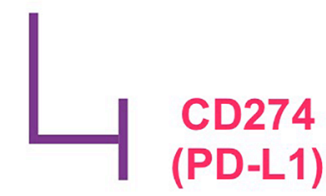


we demonstrate that total body irradiation resulted in a downregulation of the miR-25-93-106b cluster followed by an increase in CXCL12.

An important target population for CXCL12mediated recruitment and signaling are CXCR4+ cancer stem cells, which are mostly found in the invasive front and are essential for metastasis [3, 29]. The BM stromal niche provides a favorable environment for circulating tumor settlement and growth, in which CXCL12 plays a critical role in tumor cell recruitment and lodgment. CXCL12 neutralization in vivo within BM niches renders the BM less receptive and thus reduced homing,
A

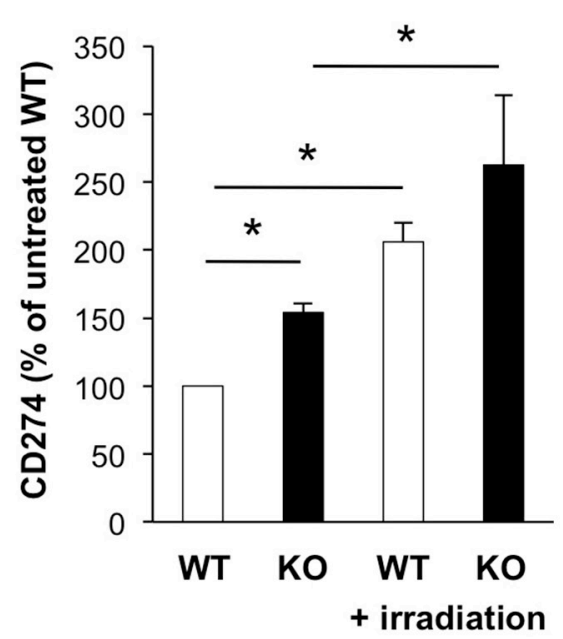

B

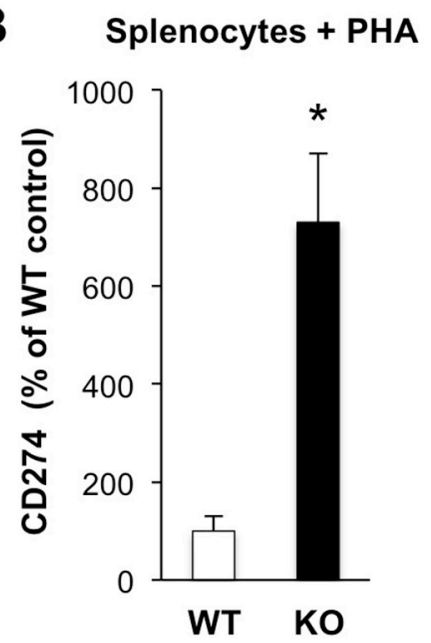

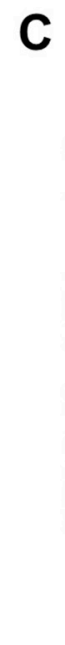

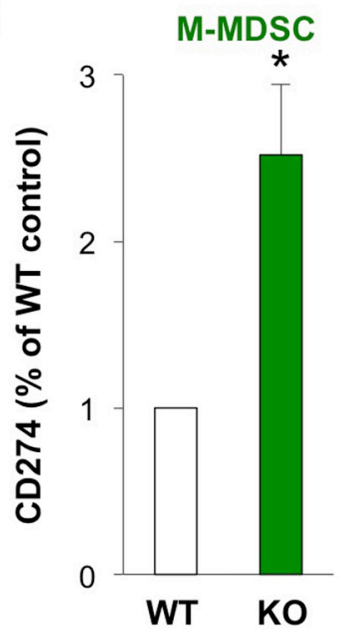

D

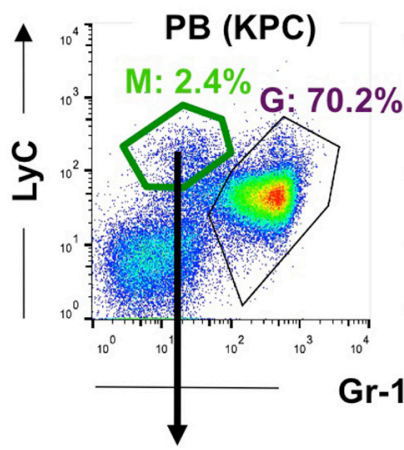

“4 Tumor (KPC)

$\mathrm{M}: 22.0 \%$



PB (KPC): M-MDSC

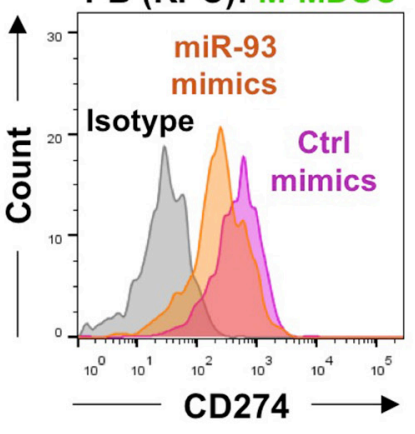

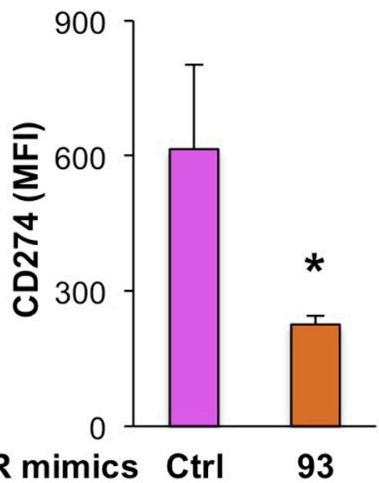

$\mathbf{E}$

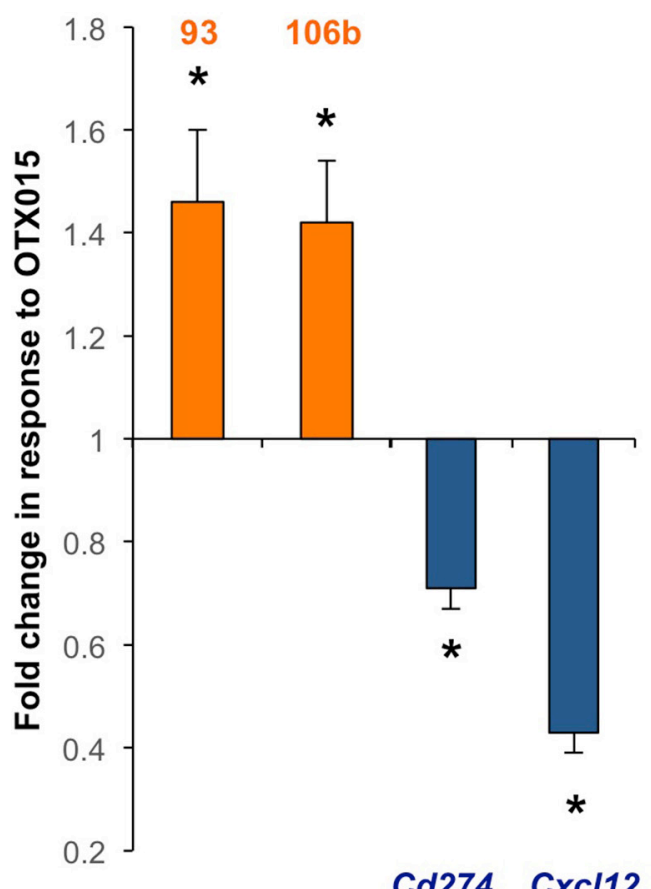

Figure 7: MiR-93/106b regulates CD274 and CXCL12 expression. A. CD274 expression in CD11b ${ }^{+}$BM cells as determined by flow cytometry 6 hours following total body irradiation. Quantification of data with untreated WT set as $100 \%$; $n=3-5, * \mathrm{p}<0.05$. B. Expression of CD274 in splenocytes following PHA activation; $n=4,{ }^{*} p<0.05$. C. Quantification of CD274 expression in sorted M-MDSC derived from WT vs miR-25-93-106b KO mice using qRT-PCR; $\mathrm{n}=4$. D. MiR-93 mimics regulate CD274 expression in M-MDSC of KPC mice. Representative flow cytometry for M-MDSC (green) and G-MDSC (purple) in the peripheral blood (PB) and pancreatic tumor (KPC) (upper). Sorted M-MDSC from PB were treated ex vivo with control or miR-93 mimics and analyzed for the expression of CD274. Representative flow cytometry (lower left) and quantification (lower right); $\mathrm{n}=3,{ }^{*} \mathrm{p}<0.05$. E. Effect of OTX015 (500nM; 72 hours) on the target genes cd274 and cxcl12 in myeloid and fibroblastoid stromal cells, $\mathrm{n}=6,{ }^{*} \mathrm{p}<0.05$. 
growth, and disease progression as shown for multiple myeloma cells [30]. Specifically, Nalm-6 pre-B acute lymphoblastic leukemia cells (ALL) have been reported to metastasize to $\mathrm{CXCL} 12^{+}$vascular niches in the $\mathrm{BM}$ due to their pronounced sensitivity to the chemoattractive cues of CXCL12 [31]. Using CXCL12-sensitive Nalm-6 cells to detect changes in the BM CXCL12 gradient, we demonstrated that the regulation of CXCL12 in the BM stromal niche via the miR-25-93-106b cluster also affected homing, and thereby metastasis. These findings should have implications for other cancers as CXCL12/CXCR4 signaling has been demonstrated as a driving mechanism for many cancers including pancreatic cancer [3,4].

Next, we found that miR-93/106b also regulated CD274, e.g. in response to irradiation. The latter is not only used as total body irradiation for BM transplantation but also as radiotherapy for the treatment of primary and metastatic cancer. Paradoxically, our data suggest that ionizing irradiation may induce multiple resistance mechanisms that could facilitate tumor relapse, e.g. via enhancing CXCL12 and also CD274/CD279 (PD-L1/PD-1) signaling, thus limiting anti-tumor immunity [32,33]. Specifically, cancer cells and MDSCs in the tumor microenvironment upregulate PD-L1 (CD274) to suppress anti-tumor immunity by inhibition of the $\mathrm{T}$ cell-mediated cytotoxicity $[32,33]$. MDSCs are categorized as a group of immature monocytic and granulocytic myeloid-derived suppressor cells, in which hypoxia has been demonstrated to upregulate CD274 via hypoxia-inducible factor-1 (HIF-1). Blockade of CD274 diminished MDSC-mediated T cell suppression by modulation of the MDSC-produced cytokines [34]. To date, however, only a few studies have investigated the regulation of $\mathrm{CD} 274$ by $\mathrm{miR}$, e.g. a study showing the role of miR-513 in modulating CD274 in human cholangiocytes [35]. Another study determined that miR197 is downregulated in chemoresistant non-small-cell lung cancer, and restoring miR-197 using miR mimics resensitizes CD274 $4^{\text {high }}$ drug-resistant cells to chemotherapy [36]. Our data now demonstrate that expression of CD274 in MDSC is regulated by the miR-25-93-106b cluster and its expression can be reduced significantly by the use of miR-93 mimics. It is important to note, however, that the contribution of CD274 expression on non-tumor cells to inhibit the anti-tumor response has at least been questioned[37] and recent studies in pre-clinical lung cancer models also suggested a more dominant role for cancer cell-derived CD274 [38]. It has been reported that CD274 is induced on murine melanoma cells upon communication with BM-derived $\mathrm{CD}_{11 \mathrm{~b}^{+}}$cells $\mathrm{BM}$ derived immune cells [39].

Consistently, we found that medium conditioned by macrophages as the most abundant and pro-tumorigenic cell population in the tumor microenvironment [20], further enhanced CD274 expression in pancreatic cancer cells. We used pancreatic cancer cells as a role model of a disease with very strong immunosuppressive properties
[40]. While many human cancers such as advanced melanoma showed impressive response to treatment with immune checkpoint inhibitors, patients with pancreatic cancer did not respond to immunological checkpoint antagonists, although cancer cell-specific $\mathrm{CD}^{+} \mathrm{T}$ cells were certainly present $[41,42]$. However, after depletion of fibroblast activation protein (FAP) $)^{+}$stromal cells producing CXCL12 in the tumor, immune control of PDAC growth could be achieved by the synergistic action of a CXCL12 receptor chemokine (C-X-C motif) 4 inhibitor and anti-PD-L1 [43], an approach that is currently tested in a clinical Phase 2 trial for patients with metastatic pancreatic cancer. Here, our data suggest that expression of CD274 in pancreatic cancer cells and the surrounding immunosuppressive MDSC is inhibited by miR-93 and 106b. Therefore, our work identifies a crucial dual role for the miR-25-93-106b cluster in the regulation of both CXCL12 and CD274, thereby mimicking the synergistic action of CXCL12 and PD-L1 inhibition, and suggests therapeutic potential for therapy-resistant PDAC.

While the clinical translation of our finding based on the use of miR mimics to modulate CXCL12 and PD-L1 may be considered challenging, we have been able to enhance the expression of the miR-25-93-106b cluster using a clinical grade BET inhibitor, i.e. OTX015. This molecule reversibly binds the BET proteins BRD2, $\mathrm{BRD} 3, \mathrm{BRD} 4$, and BRDT, and prevents protein-protein interactions between BET proteins and acetylated histones and transcription factors. BET inhibitors attenuate cell growth and survival in several hematologic cancer models [44], but also in pancreatic cancer models [45], at least in part through the down-regulation of the critical oncogene MYC. However, the mode of action of BET inhibitors is multifaceted, cell type-dependent, and may involve a broad signaling and transcriptional rewiring of both tumor cells and the tumor stroma. Here we demonstrate for the first time that BET inhibitors are able to induce miR-93/106b in the stromal microenvironment that could be important for developing more effective combination treatments. Indeed, pancreatic cancer patients have been shown to be mostly resistant to PD-1 inhibition [46] and also BET inhibitors alone only transiently slowed tumor progression [47]. Based on the data presented herein, it will be interesting to now study the effects of PD-1 inhibitors in combination with BET inhibitors in order to enhance the efficacy of checkpoint targeting.

\section{MATERIALS AND METHODS}

\section{miRNA expression array}

Total RNA was fluorescently labeled (Sham: Hy3; ischemia: Hy5) and hybridized to topic-defined PIQOR ${ }^{\mathrm{TM}}$ miRXplore Microarrays. Fluorescence was detected using a laser scanner from Agilent (Agilent Technologies). Our data represent the average values for 10 mice per group. 
Data were subsequently ranked for average miRNA expression.

\section{Flow cytometry}

CD45- BM stromal cells were stained using antimouse CD45-APC, CD45-FITC, CD45-PE, SCA-1PE (all BD Biosciences), CD140a (PDGFRa)-PECy7, and CD274-APC (both Biolegend). Myeloid cells were identified using CD11b-FITC (Biolegend) or CD11bPerCP-Cy5.5 (eBiosciences). MDSC were stained using CD11b-PerCP Cy5.5, Gr-1-PECy7 (eBiosciences), $\mathrm{k}$ and LyC-Alexa700 (Biolegend). For intracellular staining of CXCL12, cells were fixed with $4 \%$ paraformaldehyde, permeabilized in $0.1 \%$ Triton $\mathrm{X}$ (PBS-T), and stained with SDF-1-Fluorescein (R\&D; IC350F, 1:10). For surface staining, antibodies were used at 1:50 in PBS for $10 \mathrm{~min}$ at room temperature and live cells negative for 4',6-Diamidino-2-phenylindol (DAPI; Sigma: $1 \mu \mathrm{g} / \mathrm{ml}$ ) were analyzed on the Fortessa or sorted with the ARIA II cell sorter (both BD).

\section{RT-qPCR}

Total RNA was isolated using QIAzol (Qiagen) and complementary DNA synthesized (for miRNA: NCode VILO miRNA cDNA synthesis kit; for non-miRNA: SuperScript VILO cDNA synthesis kit; both Invitrogen). MiR qPCR was performed using Express SYBR GreenER Supermix with premixed ROX (Invitrogen). SNORD95 was used as housekeeping gene for miR to normalize the $\mathrm{Ct}$ values $(\Delta \mathrm{Ct})$, and relative expression was calculated using the $2^{-\Delta \Delta \mathrm{Ct}}$ method. Primers for miRNA qPCR for miR-25, miR-93, miR-106b, and SNORD95 were purchased from Qiagen. For mRNA, QPCR was performed using PerfeCTa SYBR Green fastMix low Rox (Quanta Biosciences). Ct values were normalized to housekeeping genes such as HPRT, GAPDH, and Rps29 $(\Delta \mathrm{Ct})$, and relative expression was calculated using the $2^{-\Delta \Delta \mathrm{Ct}}$ method. The list of primers can be found in Supplementary Table 1.

\section{In vivo experiments}

Unilateral hind limb ischemia was induced by ligating the deep and superficial femoral artery with an electrocoagulator and validated using this In Vivo Imaging System IVIS-200 as described previously [48]. Myocardial infarctions were created by ligating the left anterior descending coronary artery. Scar size was quantified with Image J (NIH) using the midline method [49]. BM transplantation was carried out as previously described [50]. Briefly, recipient mice were irradiated with $12 \mathrm{~Gy}$ total body irradiation given in a single dose. Twentyfour hours later, donor BM cells were intravenously administered by retro-orbital plexus injection. Mice constitutively expressing the far-red fluorescent protein
Katushka were a kind gift of Sagrario Ortega (CNIO). For in vivo homing analysis, recipient mice were irradiated with $12 \mathrm{~Gy}$ and treated with $80 \mathrm{mg} / \mathrm{kg}$ Cyclosporine A i.p. $24 \mathrm{~h}$ prior to the i.v. injection of $2 \times 10^{6} \mathrm{DiD}$-labeled donor cells [51]. Mice were sacrificed 6 or $48 \mathrm{hrs}$ later for flow cytometry of the BM [52]. All animal procedures were conducted in accordance to the $3 \mathrm{Rs}$ and were approved by the Institute's Institutional Animal Care and Use Committee (CBA 68_2013 \& CBA 25_2009 \& PPL708129).

\section{miRNA inhibitors/mimics}

MiR were inhibited using mmu-miR-93 antagomiRs $\left(5^{\prime} \rightarrow 3^{\prime}: \mathrm{C}^{*} \mathrm{U}^{*} \mathrm{~A}\right.$ CCU GCA CGA ACA GCA C*U*U *U*G, *phosphorothiates), mmu-miR-106b antagomiRs (A*U*C UGC ACU GUC AGC AC*U *U*U*A), or scrambled control $\left(\mathrm{A}^{*} \mathrm{~A} * \mathrm{G} * \mathrm{C} * \mathrm{AC}\right.$ GCG $\mathrm{CGU}$ UGA $\mathrm{GA}^{*} \mathrm{~A} * \mathrm{U} * \mathrm{U} * \mathrm{G}$ ) at $1.2 \mu \mathrm{M}$ (Biospring). MiR93, miR-106b mimics, or control mimics were used at 200pmol/24-well). To induce miR106 knockdown, cells were transduced with a lentiviral construct for miR106b knockdown identified by expression of GFP (miR106b OFF GFP; LentimiRa-Off-mmu-miR-106b-5p Vector, Applied Biological Materials, Richmond, Canada).

\section{Invasion/migration assays}

First, CD45- WT BM cells or MSC were seeded into the lower wells in in $200 \mu$ RPMI medium $+2 \%$ B-27 supplement (Thermo Fisher Scientific), grown to $80 \%$ confluency, and treated with antagomirs for $6 \mathrm{hrs}$. BD Matrigel ${ }^{\text {TM}}$-precoated inserts, $8 \mu \mathrm{m}$ pore size, were seeded with $5 \times 10^{4} \mathrm{BM}$ or Nalm- 6 cells using the same medium in the absence or presence of AMD3465 (10 $\mu \mathrm{M}$; Tocris Bioscience), inserted into above wells, and allowed to transmigrate for $42 \mathrm{hrs}$. Transmigrated cells were fixed with $4 \%$ paraformaldehyde, stained with DAPI $(1: 2,500)$, imaged by confocal microscopy, and images were analyzed using Imaris 8.0 software (Bitplane) applying the Imaris spot detection algorithm to assign a spot for each fluorescent intensity of a single nucleus. For migration studies, cells were labeled with the far red cell tracker DiD (Vybrant ${ }^{\mathrm{TM}}$ cell-labeling solution; ThermoFisher Scientific). 6-channel $\mu$-slide ( $\mu$-slide VI ${ }^{0.4}$; ibidi) were pre-filled with complete RPMI $+2 \%$ FCS $+10 \mu \mathrm{M}$ cyclosporine A (Sigma, to prevent xenogeneic response). One side was loaded with femora and tibiae fragments from mice irradiated with $12 \mathrm{~Gy}$, whereas the other side was loaded with $10^{4} \mathrm{DiD}^{+}$Nalm- 6 cells. The number of cells that passed beyond mid-way of the channel by $20 \mathrm{~h}$ were scored as migrating cells. In a modification of this assay, we used $1 \times 10^{5}$ miR-106b OFF PDAC cells with or without CXCL12 CRISPR/Cas9 knockout as target cells and allowed $1 \times 10^{3}$ (low number) Nalm-6 cells or $1 \times 10^{5}$ (high number) Nalm-6 cells to migrate towards the target cells for $20 \mathrm{~h}$. 


\section{Primary PDAC cultures}

Pancreatic tumors were obtained from murine pancreatic cancer models (Ela-KRAS and KPC) or patientderived xenografts as described previously[53]. Tumors were homogenized using a gentleMACS dissociator followed by enzymatic digestion with collagenase $\mathrm{P}$ for $15 \mathrm{~min}$ at $37^{\circ} \mathrm{C}$, and cultured in DMEM $+10 \%$ FCS. Outgrowing epithelial clones were then further expanded to heterogeneous cancer cell cultures. Stromal cells were mechanically removed by cell scraping and cultured separately. For some experiments, we required murine stromal cell rich primary PDAC cultures and used the stroma rich CKT111 PDAC cultures with mesenchymal features. Culture under low adhesion conditions to enrich for cancer stem cells and human pancreatic cancer xenografts have been described previously [54]. In some experiments, cells were treated with the BET inhibitor OTX015 (Cayman Chemicals; 500nM). To culture spheres enriched in cancer stem cells, cells were re-suspended in 1X DMEM/F-12 (Gibco $\left.{ }^{\mathrm{TM}}\right)$ supplemented with $20 \mathrm{ng} / \mathrm{ml}$ FGF-2 (CellGS), 0.4\% Amphotericin B, 1\% Penicillin/ Streptomycin, 2\% B27 supplement $\left(\mathrm{Gibco}^{\mathrm{TM}}\right)$ and $200 \mathrm{mM}$ of L-glutamine $\left(\mathrm{Gibco}^{\mathrm{TM}}\right)$. A cell suspension of $10,000 \mathrm{cells} / \mathrm{ml}$ was then prepared and distributed into ultra-low attachment surface flasks (Corning, NY, NY) for one week. Prior to use, spheres were filtered ( $40 \mu \mathrm{M}$ for human spheres, $20 \mu \mathrm{M}$ cell strainer for murine spheres).

\section{Generation of Cxcl12 knock-out cells}

Cxcl12 knock-out clones were generated using CRISPR/Cas9 gene editing as previously described [55]. Briefly, 4 sgRNAs targeting exon 2 of mouse Cxcl12 were cloned into the lentiCRISPR v2 backbone (a gift from Feng Zhang; Addgene plasmid \# 52961) and transfected into CKT111 cells. Single cell-derived clones were generated following puromycin selection and Cxcl12 knock-out was validated by ELISA for murine CXCL12 (Duoset, R\&D) from cell culture supernatants. We used the following targeting sgRNA sequences: sg\#1 TGAGCTACCGATGCCCCTGC; sg\#2 CAGA TGCTTGACGTTGGCTC; sg\#3 GATTTTCAGATGC TTGACGT; sg\#4 TGACGTTGGCTCTGGCGATG.

\section{3'UTR luciferase reporter assays}

The 3'UTR-Cxcl12 Gaussia luciferase reporter construct $(2 \mu \mathrm{g}$ per 24 -well) and a control 3'UTR-reporter construct (all from Genecopoeia) were transfected into HEK293T cells using Lipofectamine (Invitrogen). Cotransfection per 24-well (containing $5 \times 10^{4}$ cells) was performed with double-stranded miR-93 mimic, miR-106b mimic, or control mimic (Sigma; all at 200pmol/24-well). In addition, a Renilla Luciferase reporter construct was used as a transfection efficiency control for normalization (0.6 $\mu \mathrm{g}$ per $24-w e l l)$. Secreted Gaussia luciferase activity was measured using the Secrete-Pair ${ }^{\circledR}$ Dual Luminescence Assay Kit (Genecopoeia). Renilla luciferase activity was measured using the Dual-Luciferase ${ }^{\circledR}$ Reporter Assay System (Promega).

\section{Immunostaining}

For the live confocal microscopy of migrated $\mathrm{DiD}^{+}$ cells, nuclei were counterstained with Hoechst (Hoechst $33342 ; 1 \mu \mathrm{g} / \mathrm{ml}$ ), and the bones (sternum) placed into an Attofluor TM cell chamber (Life Technologies) for viewing live specimens prior to analysis using a Leica SP5 confocal microscope for the presence of $\mathrm{DiD}^{+} \mathrm{Nalm}-6$ cells. For the confocal analysis of CXCL12 expression in the BM of WT and Mir-25-93-106b-KO bone fragments, we fixed the bones in $4 \%$ paraformaldehyde for $10 \mathrm{~min}$ at room temperature, washed twice with PBS, incubated in PBS $+0.1 \%$ Triton $\mathrm{X}$ (PBS-T) for $15 \mathrm{~min}$ at room temperature, followed by incubation of the CXCL12Fluorescein (R\&D; IC350F) antibody 1:10 in PBS-T for $30 \mathrm{~min}$ at room temperature. Nuclei were counterstained with DAPI (Sigma, $1 \mu \mathrm{g} / \mathrm{ml}$ ) prior to analysis using a Leica SP5 confocal microscope.

\section{Immunohistochemistry}

Bone fragments from sternum were harvested, fixed in $10 \%$ neutral buffered formalin, decalcified, and then paraffin embedded. Immunohistochemical staining on $2.5 \mu \mathrm{M}$ sections was carried out using the Ventana Discovery XT system (Roche). Sections were deparaffinized, hydrated, and loaded on the Discovery XT. Antigen retrieval was performed using citrate buffer solution. Endogenous peroxidases were quenched using $\mathrm{H}_{2} \mathrm{O}_{2}$ reagent (Ventana). Primary antibodies against myeloperoxidase and factor VIII (both Dako, rabbit polyclonal, diluted 1:300), and CD31 (Abcam; rabbit polyclonal, diluted 1:50), and CD274 (Cell Signaling; diluted 1:150, rabbit $\mathrm{mAb}$ recognizing endogenous levels of total PD-L1 protein), were incubated for $20 \mathrm{~min}$ and detected using an anti-rabbit secondary antibody and the ChromaMap DAB detection kit (Ventana). Tissues were counterstained with hematoxylin and image analysis was performed using Pannoramic Viewer Software (3DHISTECH).

\section{miR in situ hybridization (ISH)}

ISH for miR-106b was performed as previously described [56]. Briefly, FFPE sections at $5 \mu \mathrm{m}$ thickness were deparaffinised, rehydrated and boiled with $0.01 \mathrm{M}$ sodium citrate buffer $(\mathrm{pH} 6)$ for 10 minutes. The samples were then prehybridised for 20 minutes at $48^{\circ} \mathrm{C}$, before incubating with $25 \mathrm{nM}$ DIG-labelled LNA oligonucleotide probe (Exiqon) for 1 hour at $48^{\circ} \mathrm{C}$. Samples were blocked with $5 \%$ sheep serum for 1 hour at room temperature, then incubated with alkaline phosphatase-conjugated 
anti-DIG antibody $(1: 1,000)$ overnight at $4^{\circ} \mathrm{C}$. Slides were developed with NBT/BCIP for 30min, then lightly counterstained with methyl green before dehydration and mounting.

\section{Statistical analysis}

Unless stated otherwise, results are expressed as the means \pm SEM. Statistical analyzes were performed with SPSS 22.0 (San Diego, CA) comparing continuous variables by non-parametrical Mann-Whitney $U$ and Kruskal-Wallis tests. Statistical analysis of Kaplan-Meier curves is performed by the log-rank test. The significance is given as $\mathrm{p}<0.05$.

\section{ACKNOWLEDGMENTS}

We are grateful to Andrea Ventura for providing the miR-25-93-106b $b^{-1-}$ mice and Flor Diaz for mouse breeding and screening.

\section{CONFLICTS OF INTEREST}

The authors have no conflict of interest to disclose.

\section{GRANT SUPPORT}

Research was supported by the ERC Advanced Investigator Grant (Pa-CSC 233460 to C.H.) and the European Community's Seventh Framework Programme (FP7/2007-2013) under grant agreement n ${ }^{\circ} 256974$ (EPCTM-NET to C.H.) and $\mathrm{n}^{\circ} 602783$ (CAM-PaC to C.H.), the 2015 SU2C Lustgarten CRUK Pancreatic Cancer Dream Team Award (to C.H.), Pancreatic Cancer UK RIF2014 04 (to C.H.), the Human Frontiers Scientific Program (HFSP, RGP0004/2013 to M.D.) and the La Caixa Predoctoral Fellowship Programme (to M.C.).

\section{REFERENCES}

1. Hong SH, Kim KS and Oh IH. Concise review: Exploring miRNAs--toward a better understanding of hematopoiesis. Stem Cells. 2015; 33:1-7.

2. Valtieri M and Sorrentino A. The mesenchymal stromal cell contribution to homeostasis. J Cell Physiol. 2008; 217:296-300.

3. Hermann PC, Huber SL, Herrler T, Aicher A, Ellwart JW, Guba M, Bruns CJ and Heeschen C. Distinct populations of cancer stem cells determine tumor growth and metastatic activity in human pancreatic cancer. Cell Stem Cell. 2007; $1: 313-323$

4. Balic A, Sorensen MD, Trabulo SM, Sainz B Jr, Cioffi M, Vieira CR, Miranda-Lorenzo I, Hidalgo M, Kleeff J, Erkan $\mathrm{M}$ and Heeschen $\mathrm{C}$. Chloroquine targets pancreatic cancer stem cells via inhibition of CXCR4 and hedgehog signaling. Mol Cancer Ther. 2014; 13:1758-1771.

5. Sugiyama $T$, Kohara $H$, Noda $M$ and Nagasawa $T$. Maintenance of the hematopoietic stem cell pool by CXCL12-CXCR4 chemokine signaling in bone marrow stromal cell niches. Immunity. 2006; 25:977-988.

6. Greenbaum A, Hsu YM, Day RB, Schuettpelz LG, Christopher MJ, Borgerding JN, Nagasawa T and Link DC. CXCL12 in early mesenchymal progenitors is required for haematopoietic stem-cell maintenance. Nature. 2013; 495:227-230.

7. Pitchford SC, Furze RC, Jones CP, Wengner AM and Rankin SM. Differential mobilization of subsets of progenitor cells from the bone marrow. Cell Stem Cell. 2009; 4:62-72.

8. De Falco E, Porcelli D, Torella AR, Straino S, Iachininoto MG, Orlandi A, Truffa S, Biglioli P, Napolitano M, Capogrossi MC and Pesce M. SDF-1 involvement in endothelial phenotype and ischemia-induced recruitment of bone marrow progenitor cells. Blood. 2004; 104:3472-3482.

9. Ponomaryov T, Peled A, Petit I, Taichman RS, Habler L, Sandbank J, Arenzana-Seisdedos F, Magerus A, Caruz A, Fujii N, Nagler A, Lahav M, Szyper-Kravitz M, et al. Induction of the chemokine stromal-derived factor-1 following DNA damage improves human stem cell function. J Clin Invest. 2000; 106:1331-1339.

10. Zhang L, Gajewski TF and Kline J. PD-1/PD-L1 interactions inhibit antitumor immune responses in a murine acute myeloid leukemia model. Blood. 2009; 114:1545-1552.

11. Shi L, Chen S, Yang L and Li Y. The role of PD-1 and PD-L1 in T-cell immune suppression in patients with hematological malignancies. J Hematol Oncol. 2013; 6:74.

12. Luke JJ and Ott PA. PD-1 pathway inhibitors: the next generation of immunotherapy for advanced melanoma. Oncotarget. 2015; 6:3479-3492. doi: 10.18632/oncotarget.2980.

13. Olive KP, Jacobetz MA, Davidson CJ, Gopinathan A, McIntyre D, Honess D, Madhu B, Goldgraben MA, Caldwell ME, Allard D, Frese KK, Denicola G, Feig C, et al. Inhibition of Hedgehog signaling enhances delivery of chemotherapy in a mouse model of pancreatic cancer. Science. 2009; 324:1457-1461.

14. Houlihan DD, Mabuchi Y, Morikawa S, Niibe K, Araki D, Suzuki S, Okano H and Matsuzaki Y. Isolation of mouse mesenchymal stem cells on the basis of expression of Sca-1 and PDGFR-alpha. Nat Protoc. 2012; 7:2103-2111.

15. Petrocca F, Visone R, Onelli MR, Shah MH, Nicoloso MS, de Martino I, Iliopoulos D, Pilozzi E, Liu CG, Negrini M, Cavazzini L, Volinia S, Alder H, et al. E2F1regulated microRNAs impair TGFbeta-dependent cell-cycle arrest and apoptosis in gastric cancer. Cancer Cell. 2008; $13: 272-286$ 
16. Fang L, Deng Z, Shatseva T, Yang J, Peng C, Du WW, Yee AJ, Ang LC, He C, Shan SW and Yang BB. MicroRNA miR-93 promotes tumor growth and angiogenesis by targeting integrin-beta8. Oncogene. 2011; 30:806-821.

17. Li Z, Yang CS, Nakashima K and Rana TM. Small RNAmediated regulation of iPS cell generation. The EMBO journal. 2011; 30:823-834.

18. Lapidot $\mathrm{T}$ and Kollet $\mathrm{O}$. The essential roles of the chemokine SDF-1 and its receptor CXCR4 in human stem cell homing and repopulation of transplanted immunedeficient NOD/SCID and NOD/SCID/B2m(null) mice. Leukemia. 2002; 16:1992-2003.

19. Mendez-Ferrer S, Lucas D, Battista M and Frenette PS. Haematopoietic stem cell release is regulated by circadian oscillations. Nature. 2008; 452:442-447.

20. Sainz B, Jr., Martin B, Tatari M, Heeschen C and Guerra S. ISG15 is a critical microenvironmental factor for pancreatic cancer stem cells. Cancer Res. 2014; 74:7309-7320.

21. Tamai K, Nakamura M, Mizuma M, Mochizuki M, Yokoyama M, Endo H, Yamaguchi K, Nakagawa T, Shiina M, Unno M, Muramoto K, Sato I, Satoh K, et al. Suppressive expression of CD274 increases tumorigenesis and cancer stem cell phenotypes in cholangiocarcinoma. Cancer Sci. 2014; 105:667-674.

22. Taguchi T, McGhee JR, Coffman RL, Beagley KW, Eldridge JH, Takatsu $\mathrm{K}$ and Kiyono H. Detection of individual mouse splenic $\mathrm{T}$ cells producing IFN-gamma and IL-5 using the enzyme-linked immunospot (ELISPOT) assay. J Immunol Methods. 1990; 128:65-73.

23. Arabanian LS, Fierro FA, Stolzel F, Heder C, Poitz DM, Strasser RH, Wobus M, Borhauser M, Ferrer RA, Platzbecker U, Schieker M, Docheva D, Ehninger G, et al. MicroRNA-23a mediates post-transcriptional regulation of CXCL12 in bone marrow stromal cells. Haematologica. 2014; 99:997-1005.

24. Biju V, Mundayoor S, Omkumar RV, Anas A and Ishikawa M. Bioconjugated quantum dots for cancer research: present status, prospects and remaining issues. Biotechnol Adv. 2009; 28:199-213.

25. Zhang Y, Yang P, Sun T, Li D, Xu X, Rui Y, Li C, Chong M, Ibrahim T, Mercatali L, Amadori D, Lu X, Xie D, Li QJ and Wang XF. miR-126 and miR-126* repress recruitment of mesenchymal stem cells and inflammatory monocytes to inhibit breast cancer metastasis. Nat Cell Biol. 2013; 15:284-294.

26. Simone NL, Soule BP, Ly D, Saleh AD, Savage JE, Degraff W, Cook J, Harris CC, Gius D and Mitchell JB. Ionizing radiation-induced oxidative stress alters miRNA expression. PLoS One. 2009; 4:e6377.

27. Cui W, Ma J, Wang Y and Biswal S. Plasma miRNA as biomarkers for assessment of total-body radiation exposure dosimetry. PLoS One. 2011; 6:e22988.

28. Lerman OZ, Greives MR, Singh SP, Thanik VD, Chang CC, Seiser N, Brown DJ, Knobel D, Schneider RJ,
Formenti SC, Saadeh PB and Levine JP. Low-dose radiation augments vasculogenesis signaling through HIF1-dependent and -independent SDF-1 induction. Blood. 2010; 116:3669-3676.

29. Zhang SS, Han ZP, Jing YY, Tao SF, Li TJ, Wang H, Wang Y, Li R, Yang Y, Zhao X, Xu XD, Yu ED, Rui YC, et al. CD133(+)CXCR4(+) colon cancer cells exhibit metastatic potential and predict poor prognosis of patients. BMC medicine. 2012; 10:85.

30. Roccaro AM, Sacco A, Purschke WG, Moschetta M, Buchner K, Maasch C, Zboralski D, Zollner S, Vonhoff S, Mishima Y, Maiso P, Reagan MR, Lonardi S, et al. SDF-1 inhibition targets the bone marrow niche for cancer therapy. Cell Rep. 2014; 9:118-128.

31. Sipkins DA, Wei X, Wu JW, Runnels JM, Cote D, Means TK, Luster AD, Scadden DT and Lin CP. In vivo imaging of specialized bone marrow endothelial microdomains for tumour engraftment. Nature. 2005; 435:969-973.

32. Deng L, Liang H, Burnette B, Beckett M, Darga T, Weichselbaum RR and Fu YX. Irradiation and anti-PD-L1 treatment synergistically promote antitumor immunity in mice. J Clin Invest. 2014; 124:687-695.

33. Zou GM. Cancer initiating cells or cancer stem cells in the gastrointestinal tract and liver. J Cell Physiol. 2008; 217:598-604.

34. Noman MZ, Desantis G, Janji B, Hasmim M, Karray S, Dessen P, Bronte V and Chouaib S. PD-L1 is a novel direct target of HIF-1alpha, and its blockade under hypoxia enhanced MDSC-mediated T cell activation. J Exp Med. 2014; 211:781-790.

35. Gong AY, Zhou R, Hu G, Li X, Splinter PL, O'Hara SP, LaRusso NF, Soukup GA, Dong H and Chen XM. MicroRNA-513 regulates $\mathrm{B} 7-\mathrm{H} 1$ translation and is involved in IFN-gamma-induced B7-H1 expression in cholangiocytes. J Immunol. 2009; 182:1325-1333.

36. Fujita Y, Yagishita S, Hagiwara K, Yoshioka Y, Kosaka N, Takeshita F, Fujiwara T, Tsuta K, Nokihara H, Tamura T, Asamura H, Kawaishi M, Kuwano K, et al. The clinical relevance of the miR-197/CKS1B/STAT3-mediated PD-L1 network in chemoresistant non-small-cell lung cancer. Molecular therapy. 2015; 23:717-727.

37. Youn JI, Nagaraj S, Collazo M and Gabrilovich DI. Subsets of myeloid-derived suppressor cells in tumor-bearing mice. J Immunol. 2008; 181:5791-5802.

38. Chen L, Gibbons DL, Goswami S, Cortez MA, Ahn YH, Byers LA, Zhang X, Yi X, Dwyer D, Lin W, Diao L, Wang J, Roybal JD, et al. Metastasis is regulated via microRNA-200/ZEB1 axis control of tumour cell PD-L1 expression and intratumoral immunosuppression. Nat Commun. 2014; 5:5241.

39. Noh H, Hu J, Wang X, Xia X, Satelli A and Li S. Immune checkpoint regulator PD-L1 expression on tumor cells by contacting CD11b positive bone marrow derived stromal cells. Cell Commun Signal. 2015; 13:14. 
40. Kraman M, Bambrough PJ, Arnold JN, Roberts EW, Magiera L, Jones JO, Gopinathan A, Tuveson DA and Fearon DT. Suppression of antitumor immunity by stromal cells expressing fibroblast activation protein-alpha. Science. 2010; 330:827-830.

41. Joyce JA and Fearon DT. T cell exclusion, immune privilege, and the tumor microenvironment. Science. 2015; 348:74-80.

42. Winograd R, Byrne KT, Evans RA, Odorizzi PM, Meyer AR, Bajor DL, Clendenin C, Stanger BZ, Furth EE, Wherry EJ and Vonderheide RH. Induction of T-cell Immunity Overcomes Complete Resistance to PD-1 and CTLA-4 Blockade and Improves Survival in Pancreatic Carcinoma. Cancer Immunol Res. 2015; 3:399-411.

43. Feig C, Jones JO, Kraman M, Wells RJ, Deonarine A, Chan DS, Connell CM, Roberts EW, Zhao Q, Caballero OL, Teichmann SA, Janowitz T, Jodrell DI, et al. Targeting CXCL12 from FAP-expressing carcinoma-associated fibroblasts synergizes with anti-PD-L1 immunotherapy in pancreatic cancer. Proc Natl Acad Sci U S A. 2013; 110:20212-20217.

44. Roderick JE, Tesell J, Shultz LD, Brehm MA, Greiner DL, Harris MH, Silverman LB, Sallan SE, Gutierrez A, Look AT, Qi J, Bradner JE and Kelliher MA. c-Myc inhibition prevents leukemia initiation in mice and impairs the growth of relapsed and induction failure pediatric T-ALL cells. Blood. 2014; 123:1040-1050.

45. Garcia PL, Miller AL, Kreitzburg KM, Council LN, Gamblin TL, Christein JD, Heslin MJ, Arnoletti JP, Richardson JH, Chen D, Hanna CA, Cramer SL, Yang ES, et al. The BET bromodomain inhibitor JQ1 suppresses growth of pancreatic ductal adenocarcinoma in patientderived xenograft models. Oncogene. 2016; 35:833-845.

46. Brahmer JR, Tykodi SS, Chow LQ, Hwu WJ, Topalian SL, Hwu P, Drake CG, Camacho LH, Kauh J, Odunsi K, Pitot HC, Hamid O, Bhatia S, et al. Safety and activity of antiPD-L1 antibody in patients with advanced cancer. N Engl J Med. 2012; 366:2455-2465.

47. Mazur PK, Herner A, Mello SS, Wirth M, Hausmann S, Sanchez-Rivera FJ, Lofgren SM, Kuschma T, Hahn SA, Vangala D, Trajkovic-Arsic M, Gupta A, Heid I, et al. Combined inhibition of BET family proteins and histone deacetylases as a potential epigenetics-based therapy for pancreatic ductal adenocarcinoma. Nat Med. 2015.
48. Saif J, Schwarz TM, Chau DY, Henstock J, Sami P, Leicht SF, Hermann PC, Alcala S, Mulero F, Shakesheff KM, Heeschen $\mathrm{C}$ and Aicher A. Combination of injectable multiple growth factor-releasing scaffolds and cell therapy as an advanced modality to enhance tissue neovascularization. Arteriosclerosis, thrombosis, and vascular biology. 2010; 30:1897-1904.

49. Takagawa J, Zhang Y, Wong ML, Sievers RE, Kapasi NK, Wang Y, Yeghiazarians Y, Lee RJ, Grossman W and Springer ML. Myocardial infarct size measurement in the mouse chronic infarction model: comparison of area- and length-based approaches. J Appl Physiol (1985). 2007; 102:2104-2111.

50. Aicher A, Rentsch M, Sasaki K, Ellwart JW, Fandrich F, Siebert R, Cooke JP, Dimmeler S and Heeschen C. Nonbone marrow-derived circulating progenitor cells contribute to postnatal neovascularization following tissue ischemia. Circulation research. 2007; 100:581-589.

51. Fingert HJ, Treiman A and Pardee AB. Transplantation of human or rodent tumors into cyclosporine-treated mice: a feasible model for studies of tumor biology and chemotherapy. Proc Natl Acad Sci U S A. 1984; 81:7927-7931.

52. Colvin GA, Lambert JF, Dooner MS, Cerny J and Quesenberry PJ. Murine allogeneic in vivo stem cell homing(,). J Cell Physiol. 2007; 211:386-391.

53. Hermann PC, Sancho P, Canamero M, Martinelli P, Madriles F, Michl P, Gress T, de Pascual R, Gandia L, Guerra C, Barbacid M, Wagner M, Vieira CR, et al. Nicotine Promotes Initiation and Progression of KRAS-Induced Pancreatic Cancer via Gata6-Dependent Dedifferentiation of Acinar Cells in Mice. Gastroenterology. 2014; 147:1119-1133.

54. Lonardo E, Hermann PC, Mueller MT, Huber S, Balic A, Miranda-Lorenzo I, Zagorac S, Alcala S, Rodriguez-Arabaolaza I, Ramirez JC, Torres-Ruiz R, Garcia E, Hidalgo M, et al. Nodal/Activin signaling drives self-renewal and tumorigenicity of pancreatic cancer stem cells and provides a target for combined drug therapy. Cell Stem Cell. 2011; 9:433-446.

55. Sanjana NE, Shalem O and Zhang F. Improved vectors and genome-wide libraries for CRISPR screening. Nat Methods. 2014; 11:783-784.

56. de Planell-Saguer M, Rodicio MC and Mourelatos Z. Rapid in situ codetection of noncoding RNAs and proteins in cells and formalin-fixed paraffin-embedded tissue sections without protease treatment. Nat Protoc. 2010; 5:1061-1073. 